New Drugs

\title{
Novel therapeutic strategies for patients with NSCLC that do not respond to treatment with EGFR inhibitors
}

\author{
Christian Rolfo ${ }^{\mathrm{a}, *}$, Elisa Giovannetti ${ }^{\mathrm{b}}$, David S. Hong ${ }^{\mathrm{c}}$, T. Bivona ${ }^{\mathrm{d}}$, Luis E. Raez ${ }^{\mathrm{e}}$, Giuseppe Bronte ${ }^{\mathrm{f}}$, \\ Lucio Buffoni $^{\mathrm{g}}$, Noemí Reguart ${ }^{\mathrm{h}}$, Edgardo S. Santos ${ }^{\mathrm{i}}$, Paul Germonpre ${ }^{\mathrm{j}}$, Mìquel Taron ${ }^{\mathrm{k}}$, \\ Francesco Passiglia ${ }^{\mathrm{a}, \mathrm{f}}$, Jan P. Van Meerbeeck ${ }^{1}$, Antonio Russo ${ }^{\mathrm{f}}$, Marc Peeters ${ }^{\mathrm{m}}$, Ignacio Gil-Bazo ${ }^{\mathrm{n}}$, \\ Patrick Pauwels ${ }^{\circ}$, Rafael Rosell ${ }^{\mathrm{k}}$
}

\footnotetext{
a Phase I - Early Clinical Trials Unit, Oncology Department and Multidisciplinary Oncology Center Antwerp (MOCA) Antwerp University Hospital, Edegem, Belgium

${ }^{\mathrm{b}}$ Department Medical Oncology, VU University Medical Center, Amsterdam, The Netherlands

${ }^{\mathrm{c}}$ Department of Investigational Cancer Therapeutics, The University of Texas MD Anderson Cancer Center, Houston, TX, USA

${ }^{\mathrm{d}}$ Hematology and Oncology Department, Hellen Diller Family Comprehensive Cancer Center, University of California, San Francisco, CA, USA

${ }^{e}$ Memorial Cancer Institute, Memorial Health Care System, Florida International University, Miami, FL, USA

${ }^{\mathrm{f}}$ Department of Surgical, Oncological and Oral Sciences, Section of Medical Oncology, University of Palermo, Palermo, Italy

${ }^{\mathrm{g}}$ San Giovanni Battista Molinette Hospital, Department of Medical Oncology, Turin, Italy

${ }^{\mathrm{h}}$ Medical Oncology Department, Hospital Clinic, Barcelona, Spain

i Lynn Cancer Institute, Thoracic Oncology, Boca Raton, FL, USA

${ }^{\mathrm{j}}$ Department of Respiratory Medicine, AZ Maria Middelares, Kortrijksesteenweg 1026, 9000 Ghent, Belgium

${ }^{\mathrm{k}}$ Catalan Institute of Oncology, Hospital Germans Trias i Pujol, Badalona, Barcelona, Spain

${ }^{1}$ Thoracic Oncology, Multidisciplinary Oncology Center Antwerp (MOCA) Antwerp University Hospital, Edegem, Belgium

${ }^{\mathrm{m}}$ Department of Medical Oncology, University Hospital Antwerpen, Wilrijkstraat 10, 2650 Edegem, Belgium

${ }^{\mathrm{n}}$ Department of Oncology, Clinica Universidad de Navarra, Pamplona, Spain

${ }^{\circ}$ Molecular Pathology Unit, Pathology Department and Multidisciplinary Oncology Center Antwerp (MOCA) Antwerp University Hospital, Edegem, Belgium
}

\section{A R T I C L E I N F O}

\section{Article history}

Received 20 January 2014

Received in revised form 23 April 2014

Accepted 26 May 2014

\section{Keywords:}

EGFR mutations

TKI inhibitors resistance

NSCLC

New drugs

Novel therapeutic strategies

\begin{abstract}
A B S T R A C T
Introduction: Treatment with epidermal growth factor receptor (EGFR) tyrosine kinase inhibitors (TKIs) yields tumour responses in non-small cell lung cancer (NSCLC) patients harbouring activating EGFR mutations. However, even in long-lasting responses, resistance to EGFR TKIs invariably occurs. Areas covered: This review examines resistance mechanisms to EGFR TKI treatment, which mainly arise from secondary EGFR mutations. Other resistance-inducing processes include mesenchymal-epithelial transition factor (MET) amplification, epithelial-mesenchymal transformation, phenotypic change from NSCLC to small-cell lung carcinoma, and modifications in parallel signalling pathways. Current therapeutic strategies to overcome these EGFR TKI resistance mechanisms focus on the inhibition or blocking of multiple members of the ErbB family. Several molecules which target multiple ErbB receptors are being investigated in NSCLC and other indications including afatinib, an ErbB Family Blocker, as well as dacomitinib and lapatinib. Novel, non-quinazoline, EGFR inhibitors, that also target EGFR activating and resistance (T790M) mutations, are currently under clinical development. Other therapeutic strategies include inhibition of parallel and downstream pathways, using agents which target heat shock protein (HSP)90 or
\end{abstract}

Abbreviations: AEG-1, astrocyte elevated gene-1; ALK, anaplastic lymphoma kinase; ATP, adenosine triphosphate; BARD1, BRCA1-associated protein 1; BIM, B-cell

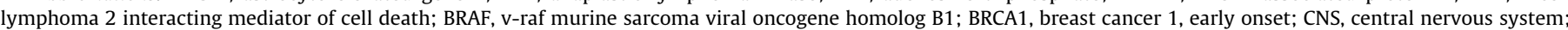

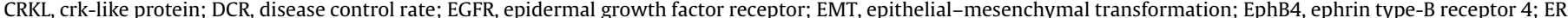

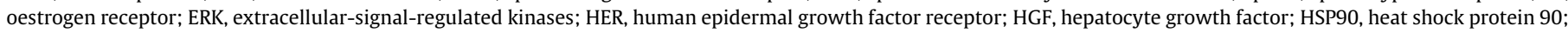

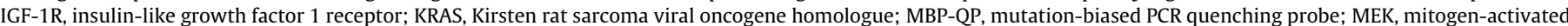

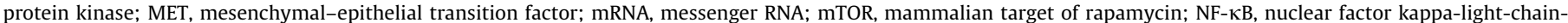

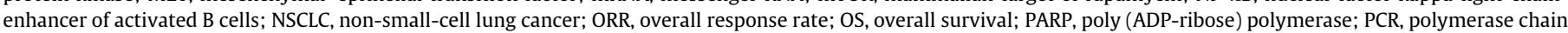

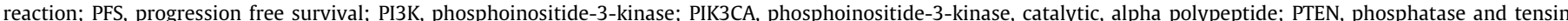

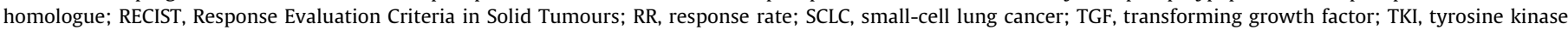
inhibitors; VEGF, vascular endothelial growth factor; VEGFR, VEGF receptor.

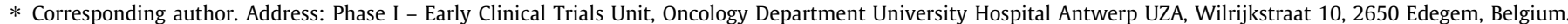
Tel.: +32 382136 46; fax: +3238251592.

E-mail address: christian.rolfo@uza.be (C. Rolfo). 
poly (ADP-ribose) polymerase in addition to mammalian target of rapamycin (mTOR), monoclonal antibodies against the insulin-like growth factor-1 receptor, and fulvestrant-mediated oestrogen receptor regulation.

Conclusion: Improved understanding of mechanisms underlying resistance to EGFR TKIs emphasises the importance of a genotype-guided approach to therapy. Elucidation of resistance mechanisms is indeed crucial to target innovative therapeutic approaches and to improve the efficacy of anticancer regimes in NSCLC.

(c) 2014 Elsevier Ltd. All rights reserved.

\section{Introduction}

Non-small cell lung cancer (NSCLC) is the most common form of lung cancer, accounting for approximately $85 \%$ of cases. Disease staging is essential in defining clinical management, and surgical resection remains the best option in early stage disease. However, $70 \%$ of patients have locally advanced or metastatic disease at diagnosis. To date first-line platinum-based chemotherapy has represented the standard treatment for these patients, achieving about $30 \%$ as response rates (RR) and an approximate 12 -months median overall survival (OS). More recently, the molecular biology of lung cancer has been shown to play an important part in its pathology. Genotyping for key mutations has become clinically relevant, guiding the success of new therapies in NSCLC compared with traditional chemotherapy [1].

\section{Development of EGFR TKIs}

One particular area of research interest has focused on the ErbB Family, whose four members - epidermal growth factor receptor (EGFR/ErbB1), human epidermal growth factor receptor 2 (HER2/ ErbB2), ErbB3 and ErbB4 - are central for the regulation of downstream signalling pathways important for tumour cell prolifera- tion, survival, migration and metastasis (Fig. 1). Targeting EGFR has become an essential strategy in the treatment of NSCLC [2].

Two reversible EGFR tyrosine kinase inhibitors (TKIs), gefitinib and erlotinib, are currently commercially available for the treatment of NSCLC. These agents were first investigated in unselected NSCLC patients with encouraging results [3-6] but subsequent trials proved disappointing [7-9]. However, more recently clinical trials have shown clinical benefit of both gefitinib and erlotinib in a specific population of NSCLC patients with tumours bearing EGFR activating mutations [10-17]. The two most common EGFR mutations, accounting for $>85 \%$ of all EGFR alterations, are in-frame deletions in exon 19 (del19) or point mutations in exon 21 (L858R) [18] while exon 18 mutations are less frequent (approximately 4\%) $[19,20]$. The del19 and L858R mutations are present in $\sim 10 \%$ of Caucasian patients and $30-50 \%$ of Asian patients with NSCLC [21] and are sensitive to treatment with reversible EGFR TKIs [22].

\section{Resistance to EGFR TKIs}

While most ( $>75 \%$ ) NSCLC patients with somatic EGFR mutations show initial responses to treatment with the reversible TKIs

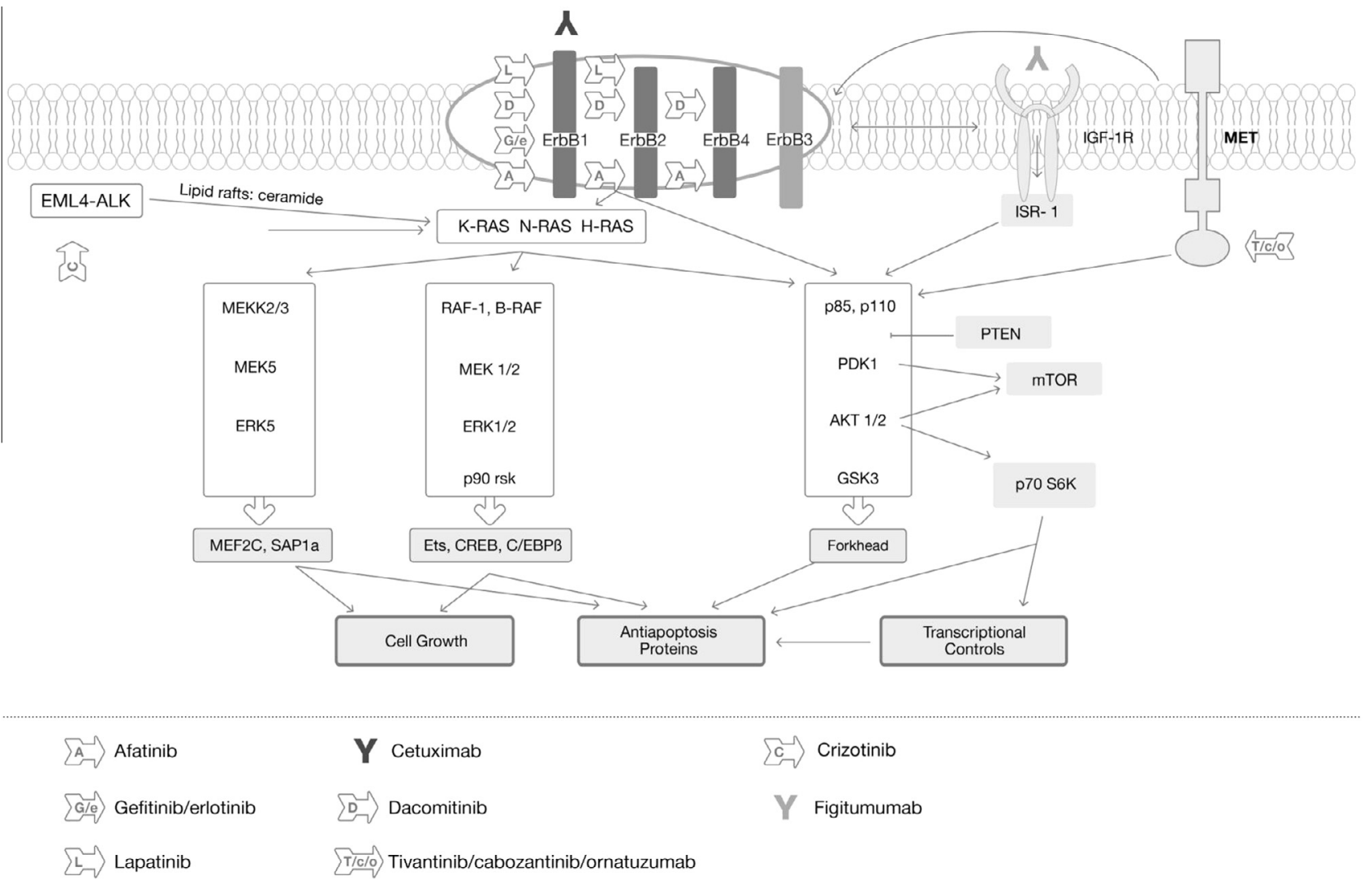

Fig. 1. Receptors and signalling pathways involved in the development of NSCLC. 
[21] they invariably develop or 'acquire' resistance to these agents $[21,23]$. There are also a number of patients who do not respond to initial treatment with reversible EGFR TKIs and these patients are deemed to have primary or de novo resistance.

\section{Primary resistance}

There are several mechanisms of primary resistance (Table 1) some of which are common to acquired resistance but are present prior to EGFR TKI treatment.

\section{De novo T790M EGFR mutation}

The primary mechanism of de novo resistance is thought to be the T790M EGFR mutation which is present before EGFR TKI treatment (31.5-35\% of tumours) [24,25] and may contribute to primary resistance. Specifically, the presence of the compound mutant EGFR is postulated to contribute to the Darwinian selection of pre-existing drug-resistant clones [26,27]. Thus, the fraction of the T790M allele would increase during EGFR TKI therapy to a threshold, which allows us to consider resistance 'acquired'. As a consequence the T790M detection rate changes from $31.5-35 \%$ in tumours pre-EGFR TKI therapy [24,25] to $83.3 \%$ post-EGFR TKI treatment [27]. These detection rates are obtained by matrixassisted laser desorption ionization-time of flight mass spectrometry (MALDI-TOF MS), which is a highly sensitive method for detection of EGFR mutations. The detection rate of T790M is $2.8 \%$ in TKI-naive patients by direct sequencing. This low prevalence of de novo T790M detected by direct sequencing may be a result of the low copy number of T790M present in patients' tumour specimens. For this reason the evaluation of studies assessing the clinical role of T790M should take into account the type of detection method utilised.

However, the existence of the T790M mutation does not necessarily indicate a poorer outcome compared with patients without the T790M mutation. Oxnard and Sordella found that the combined EGFR mutations (del19 or L858R plus T790M), identified at the time of clinical progression on erlotinib, were associated with longer survival [28]. Likewise, Fujita et al. observed that patients who were strongly positive for T790M had significantly longer time to treatment failure on reversible EGFR TKIs than patients without T790M or those with modest positivity for the mutation (frequency of positive signals obtained from colony hybridization) [24]. Finally, T790M mutations have recently been associated with better progression-free survival (PFS) in EGFR-mutant NSCLC patients receiving chemotherapy [29]. These results suggest that the presence of the T790M mutation in a tumour with activating EGFR mutations does not necessarily preclude treatment with an EGFR TKI. Secondly, T790M has a prognostic and predictive value for EGFR TKI treatment outcomes; therefore, routine assessment of the T790M mutation in the diagnostic biopsy is warranted. Moreover, a better understanding of the role of T790M is crucial for the development of effective treatments to overcome this problem.

\section{Brca1}

The expression of Breast Cancer Type 1 susceptibility protein (BRCA1) has also been evaluated as a predictive marker of outcome in NSCLC patients treated with an EGFR TKI [25]. For NSCLC patients bearing a T790M mutation pre-TKI exposure, low BRCA1

Table 1

Resistance factors (mutations) to EGFR TKIs.

\begin{tabular}{|c|c|}
\hline Type of mutation & Outcome \\
\hline \multicolumn{2}{|c|}{ Primary resistance mechanisms* } \\
\hline Basal T790M mutations & $\begin{array}{l}\text { De novo reversible EGR TKI resistance. T790M mutation associated with a } \\
\text { decreased progression-free survival in patients with NSCLC who received } \\
\text { TKI treatment [25] }\end{array}$ \\
\hline BRCA1 expression & $\begin{array}{l}\text { Low levels of BRCA1 could improve the current negative perspectives and } \\
\text { offer a longer progression-free survival with erlotinib [25] }\end{array}$ \\
\hline NF-KB signalling & $\begin{array}{l}\text { NF-KB hyperactivation predicts worse response and survival in erlotinib- } \\
\text { treated NSCLC patients harbouring EGFR-mutant tumours [30] }\end{array}$ \\
\hline $\begin{array}{l}\text { BIM expression and } \\
\text { polymorphism }\end{array}$ & $\begin{array}{l}\text { A pro-apoptotic member of the B-cell CLL/lymphoma } 2 \text { (BCL2) which has } \\
\text { an important role in resistance to EGFR TKIs [31ó34] }\end{array}$ \\
\hline \multicolumn{2}{|c|}{ Acquired resistance mechanisms* } \\
\hline Acquired T790M mutations & $\begin{array}{l}\text { Resistance to reversible EGFR TKI treatment (affects over } 50 \% \text { of the } \\
\text { cases of acquired resistance) }[24,35 \text { ó } 37]\end{array}$ \\
\hline MET amplification & $\begin{array}{l}\text { MET, a receptor tyrosine kinase, stimulates the ErbB3-dependent activation } \\
\text { of PI3K/Akt signalling, generating resistance to EGFR TKIs [39] }\end{array}$ \\
\hline HGF amplification & Has been identified as a resistance factor in NSCLC patients [41ó44] \\
\hline AXL upregulation & $\begin{array}{l}\text { Expression of } A X L \text { and its ligand, GAS6, is increased and contributes to } \\
\text { resistance in TKI-resistant EGFR-mutant NSCLC [45] }\end{array}$ \\
\hline $\begin{array}{l}\text { Epithelial-mesenchymal } \\
\text { transformation }\end{array}$ & $\begin{array}{l}\text { Common process in cancer pathogenesis and has been observed in } \\
\text { NSCLC tumours with acquired resistance to reversible EGFR TKIs [46] }\end{array}$ \\
\hline $\begin{array}{l}\text { Conversion from NSCLC to } \\
\text { SCLC }\end{array}$ & $\begin{array}{l}\text { This transition seems to be specific to cells with resistance to EGFR TKI } \\
{[46,49]}\end{array}$ \\
\hline CRKL amplification & $\begin{array}{l}\text { Induces resistance to gefitinib by activating extracellular signal-regulated } \\
\text { kinase signalling }[50,51]\end{array}$ \\
\hline
\end{tabular}

* Some mechanisms may be common to both primary and acquired resistance. BIM, B-cell lymphoma 2 interacting mediator of cell death; BRCA1, breast cancer 1, early onset; CRKL, crk-like protein; EGFR, epidermal growth factor receptor; HGF, hepatocyte growth factor; MET, mesenchymal-epithelial transition factor; NSCLC, non small cell lung carcinoma; PIK3, phosphoinositide-3-kinase; TKI, tyrosine kinase inhibitor. 
levels may improve the impact of T790M and promote a longer progression-free survival (PFS) with erlotinib. This suggests that establishing the presence of the T790M mutation and BRCA1 levels could aid appropriate treatment selection for such patients [25]. Furthermore, the coexpression of BRCA1 and the associated oncogene, astrocyte elevated gene-1, could represent a marker for prognosis in patients with wild-type EGFR and response to erlotinib treatment in patients with EGFR mutations [30].

\section{$N F-\kappa B$ signalling and $I \kappa B$}

A recent study performed a pooled shRNA screen to identify genes that, when silenced, enhanced sensitivity to the EGFR TKI erlotinib [31]. Results revealed a potentially important role for nuclear factor kappa-light-chain-enhancer of activated B cells $(\mathrm{NF}-\mathrm{KB})$ signalling in regulating EGFR oncogene dependence in EGFR-mutant NSCLC. Genetic or pharmacological inhibition of $\mathrm{NF}-\kappa \mathrm{B}$ significantly enhanced responses to erlotinib in in vitro and in vivo models of EGFR-mutant NSCLC [31]. Furthermore, clinical studies using EGFR-mutant NSCLC specimens from erlotinibtreated patients showed that NF- $\kappa \mathrm{B}$ hyperactivation, as marked by low tumour levels of I $\mathrm{KB}$, predicted worse response and survival than for patients treated with chemotherapy. Additional prospective studies validating NF- $\kappa \mathrm{B}$ signalling as a predictive biomarker of EGFR TKI response and as a therapeutic target in EGFR-mutant NSCLC patients are underway.

\section{BIM expression and polymorphisms}

BIM, also known as BCL2-like 11, is a proapoptotic protein that is overexpressed in different malignancies. BIM upregulation is required for induction of apoptosis by EGFR TKIs in EGFR-mutant NSCLC and low BIM mRNA levels are thought to be a marker of primary resistance in these tumours [32]. Indeed BIM mRNA expression has recently been shown to be a biomarker of survival in EGFR-mutant NSCLC [33]. A study by $\mathrm{Ng}$ et al. has assessed the presence or absence of the BIM deletion polymorphism in $141 \mathrm{sub}-$ jects with NSCLC from Singapore and Japan who were known to have activating mutations in EGFR and who received TKI therapy. The authors concluded that a common BIM deletion polymorphism mediates intrinsic resistance and inferior responses to EGFR TKIs in cancer [34]. Recent studies have showed that HDAC inhibition can epigenetically restore BIM function in vitro and apoptotic sensitivity to EGFR-TKI, in cases of EGFR mutant NSCLC where resistance to EGFR-TKI is associated with a common BIM polymorphism [35].

\section{Acquired resistance}

In 2010, Jackman et al. proposed criteria to define and classify acquired resistance to EGFR TKIs in NSCLC patients with somatic EGFR gene mutations (Table 2) [22]. Many mechanisms of acquired drug resistance to reversible EGFR TKIs have been postulated (Table 1).

\section{EGFR resistance mutations}

In approximately $50-83 \%$ of EGFR mutation-positive NSCLC patients, resistance to a reversible EGFR TKIs is attributed to development or acquirement of a second EGFR mutation, the T790M mutation [24,36-38]. Several other mutations, including D761Y, L747S and T854A, have also been implicated in acquired resistance in patients who have previously responded to EGFR TKIs $[2,39]$. The reports of these mutations are rare and mainly attributed to single patient case reports in the literature but they do demonstrate the role of secondary mutations in acquired resistance.

\section{MET and HGF amplification}

Another significant group of cancers (approximately 20\%) acquire resistance to reversible EGFR TKIs following the amplification of the mesenchymal-epithelial transition factor (MET) receptor tyrosine kinase (RTK), which in combination with ErbB3 activates different signalling pathways from EGFR [40]. MET, an RTK and its ligand, hepatocyte growth factor (HGF), regulate multiple cellular processes that stimulate cell proliferation, invasion, and angiogenesis. Alterations in MET (mutation, amplification or translocation) can produce tumourigenic effects. MET amplification stimulates the ErbB3-dependent activation of phosphoinositide-3-kinase (PI3K)/Akt signalling, which by-passes the effects of EGFR TKIs [40]. MET amplification is detected in 7\% of EGFR TKInaïve NSCLC patients who undergo surgical resection and approximately $20 \%$ of patients with acquired EGFR TKI resistance [40,41]. Evidence suggests that EGFR inhibition induces HGF-mediated clonal selection of pre-treatment MET amplification [42]. HGF is, therefore, another important resistance factor in NSCLC patients [43]. It is tempting to speculate that HGF production by stroma may also partly explain the discordant emergence of clinical resistance in some tissues such as liver, bone and brain, while pulmonary disease continues to respond to erlotinib treatment [42]. Researchers have discovered that HGF induces gefitinib resistance by restoring the PI3K/Akt pathway through Gab1, but not via EGFR or ErbB3 $[42,43]$. A recent study showed that the transient blockade of the PI3K/Akt pathway by PI-103 and gefitinib could overcome HGF-mediated resistance to EGFR TKIs by inducing apoptosis in EGFR-mutant lung cancer [44]. These observations suggest that targeting MET and HGF may counteract TKI resistance in EGFR-mutant lung cancer. However HGF overexpression detected by immunohistochemistry showed a favourable prognostic value [45].

\section{AXL upregulation}

AXL is a member of the TAM (Tyro3-AXL-Mer) family of RTKs, assuming broad functions in tumour cell growth, proliferation, migration, adhesion and chemosensitivity. An important and previously underappreciated role for AXL signalling in acquired EGFR TKI resistance in EGFR-mutant NSCLC was recently revealed [46]. In TKI-resistant EGFR-mutant NSCLC, increased expression of AXL and its ligand, GAS6 was observed and was required for resistance; genetic or pharmacological AXL inhibition restored sensitivity to

\section{Table 2}

Proposed criteria for acquired resistance to EGFR TKIs in NSCLC (adapted from Jackman et al., 2010) [22].

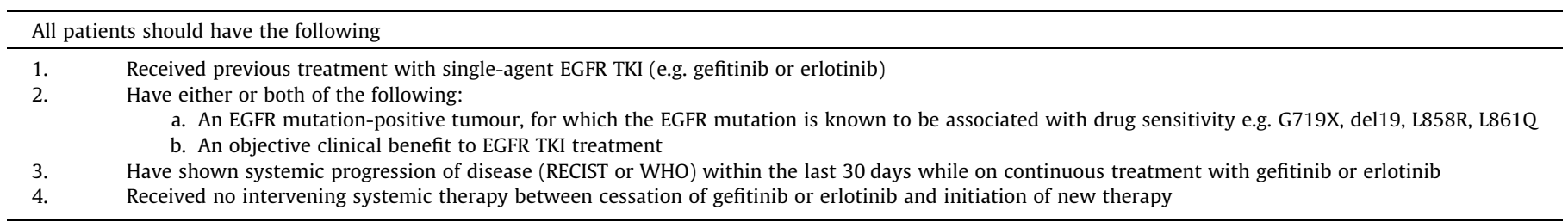

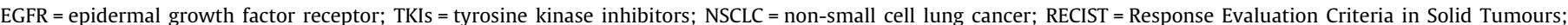
WHO = World Health Organization . 
erlotinib. Interestingly, elevated AXL and GAS6 co-existed with T790M in a minority of tumours, suggesting that these mechanisms may cooperate to promote resistance. In contrast, upregulation of AXL and MET was not shown, indicating that AXL or MET kinase activation alone is sufficient to function as a kinasemediated bypass mechanism of EGFR TKI resistance. Prospective validation of AXL and GAS6 as biomarkers of EGFR TKI resistance and evaluation of promising therapeutic targets in EGFR-mutant NSCLC are ongoing.

\section{Epithelial-mesenchymal transformation}

Epithelial-mesenchymal transformation (EMT) is a common process in cancer pathogenesis and has been observed in NSCLC tumours with acquired resistance to reversible EGFR TKIs [47]. EMT includes processes underlying an increased potential for cancer cells to migrate to other tissues, such as the loss of epithelial cell characteristics and the development of new mesenchymal markers.

EMT has been associated with EGFR TKI resistance because cell behaviour can vary depending on their transformation stage. For example, cells containing wild-type EGFR that retained certain epithelial characteristics, such as E-cadherin expression, were more sensitive to erlotinib, whereas those that expressed mesenchymal markers such as vimentin and/or fibronectin were erlotinib-resistant [48]. A recent study suggested that MED12 loss induces an EMT-like phenotype associated with resistance to chemotherapy in colon cancer and to gefitinib in lung cancer [49]. As MED12 is partly cytoplasmic (where it negatively regulates transforming growth factor [TGF]- $\beta R 2$ through physical interaction), TGF- $\beta R$ inhibition restores drug responsiveness in MED12(KD) cells, highlighting a strategy to treat drug-resistant tumours with MED12 loss [49]. Interestingly, a recent study, also reported a relationship between EMT and erlotinib acquired resistance in an erlotinib sensitive lung cancer cell-line harbouring an EGFR deletion mutation. The authors found that cells acquired mesenchymal phenotype and exhibited down-regulation of E-cadherin expression, while the Histone deacetylase inhibitor, MS-275, restored E-cadherin expression and partial sensitivity to erlotinib [50]. Expression studies of these markers may be a very important source of diagnostic information.

\section{Conversion of NSCLC to SCLC}

Sequist et al. first described certain phenotypic changes in tumours with acquired resistance to TKIs. These changes affected a significant number of patients (14\% of those studied) presenting with NSCLC whose biopsies - taken at the time of TKI resistance revealed a small-cell lung cancer (SCLC) phenotype [47]. This transformation may be indicative of a pluripotent population of EGFR-mutant cancer cells or cancer stem cells as the source of resistance. The transition from NSCLC to SCLC appears specific to EGFR TKI-resistant cells. While the original EGFR mutation was maintained in all patients, none developed EGFR T790M or MET amplification. These patients received etoposide-based chemotherapy and showed a response similar to 'classical' SCLC. More recently, however a study by $\mathrm{Yu}$ et al. has shown that in EGFR mutation-positive NSCLC patients with acquired resistance to reversible EGFR TKIs, T790M, MET amplification and SCLC transformations have also been simultaneously observed [51]. Therefore, rebiopsy in lung cancer patients with acquired resistance to EGFR inhibitors can provide information about tumour cell phenotype, which can be relevant to choose an appropriate therapeutic strategy.

\section{CRKL amplification}

Multiple NSCLC cell lines and 3\% of lung cancer specimens exhibit high-level amplification at cytoband 22q11.21 containing the crk-like protein $(C R K L)$ gene, which contributes to cell proliferation and survival [52]. CRKL over-expression promotes anchorage-independent growth and tumourigenicity via SOS1-RAS-RAF-ERK and SRC-C3G-RAP1 pathway activation. Description of CRKL overexpression in an EGFR mutant cells induces resistance to gefitinib. The appearance of CRKL amplification in lung adenocarcinoma post-treatment with EGFR-inhibitors, suggests CRKL as an additional mediator of acquired resistance to epidermal growth factor receptor (EGFR)-inhibitors and credential it as a potential therapeutic target for a subset of NSCLC [52]. Hence, amplification and over-expression of CRKL contribute to oncogenic phenotypes in lung cancer, with relevance for therapy [53].

Other receptor mutations and signalling pathways involved in EGFR TKI resistance

Several receptor mutations as well as other signalling pathways and receptors have been shown to be modified in EGFR TKIs resistant tumours. These include increased expression of vascular endothelial growth factor (VEGF) which has been shown post-TKI therapy in patients with different malignancies, including squamous cell carcinoma and GEO (well differentiated colon cancer cell line). The insulin-like growth factor-1 receptor (IGF-1R) has been described as activating many of the same signalling pathways as EGFR [54]. EGFR TKI treatment increased IGF-1R expression, leading to the activation of PI3K/Akt signalling and increased resistance to EGFR TKIs [55]. In about 5\% of NSCLC patients harbouring EGFR mutations, who developed resistance to EGFR TKIs, phosphoinositide-3-kinase, catalytic, alpha polypeptide (PIK3CA) mutation has been identified [47]. v-Raf murine sarcoma viral oncogene homo$\log$ B1 (BRAF) mutations, which affect the RAS pathway, have also been observed in $1 \%$ of tumours with acquired resistance [56]. HER2 amplication has been detected in NSCLC inducing an unfavourable prognostic value. It is mutually exclusive with T790M mutation in EGFR and has been found in 12\% of lung cancers which developed resistance to EGFR TKIs [57]. MAPK1 can also be amplified in lung cancer patients with acquired resistance to EGFR TKIs and has been identified in $5 \%$ of these patients and is mutually exclusive with both EGFR T790M mutation and MET amplification [58]. More recently preclinical work has shown that resistance to the EGFR TKI erlotinib is associated with reduced expression of neurofibromin [59]. Neurofibromin is a RAS GTPase encoded by the NF1 gene. Erlotinib failed to fully inhibit RAS-ERK signalling when neurofibromin levels were reduced but treatment of neurofibromin-deficient lung cancers with a mitogen-activated protein kinase (MEK) inhibitor restored sensitivity to erlotinib. Furthermore, low levels of NF1 expression have been observed in EGFR TKI resistant lung adenocarcinoma patients [59]. Other potential mechanisms include upregulation of JAK2, an upstream STAT signalling pathway, and phosphatase and tensin homologue (PTEN) loss $[2,60]$.

\section{Monitoring resistance to EGFR TKI}

Large-scale EGFR mutation screening interventions based on tumour tissue samples have proven their utility in NSCLC and can play an important role in clinical treatment decisions [61]. However, obtaining tumour tissue is challenging; for this reason, more sensitive and/or non-invasive techniques requiring a small amount of tissue or involving nucleic acid genotyping in blood samples have been tested for implementation in clinical practice.

\section{New polymerase chain reaction techniques}

Aside from BRCA1, other genes potentially involved in erlotinib resistance have been explored using NanoString ${ }^{\circledR}$ [62]. This tool 
utilises digital technology based on a direct multiplexed measurement of targeted gene expression, allowing the expression analysis of 48 genes in a single reaction. Using NanoString ${ }^{\circledR}$, both BRCA1associated protein 1 (BARD1) and astrocyte elevated gene-1 (AEG-1) were found to predict PFS in erlotinib-treated EGFRmutant NSCLC [62]. Hence, wider adoption of NanoString ${ }^{\circledR}$ may have important implications for optimal NSCLC management.

\section{Peripheral blood samples for monitoring EGFR mutations}

In NSCLC patients for whom obtaining tissue samples is challenging non-invasive tissue sampling methods could be useful. Blood samples drawn from NSCLC patients may serve as a source of tumoural DNA for the detection of EGFR mutations. The equivalence of EGFR mutations in serum samples and matched tumour tissue from patients with advanced disease was shown using two detection methods, mutant-enriched polymerase chain reaction (PCR)-based DNA sequencing and non-enriched sequencing [63]. A reported concordance rate of $93.1 \%$ for mutant-enriched sequencing supports its recommendation for routine practice.

Results obtained with a new non-invasive method for determining the presence of T790M using DNA extracted from plasma samples - the mutation-biased PCR quenching probe (MBP-QP) [64] - were comparable with other non-invasive DNA-based mutation detection systems. However, the MBP-QP method confers major advantages in terms of simplicity and sensitivity for detecting T790M in plasma samples, suggesting real utility in standard care.

\section{Strategies for overcoming resistance to EGFR TKIs}

New drugs affecting the ErbB signalling pathways

Recently, attention has focused on the simultaneous blocking of multiple members of the ErbB Family, achieving prolonged inhibition of EGFR signalling and reducing the development of resistance. Several new agents that block or inhibit the ErbB signalling pathways are currently under development or have been recently approved (afatinib in NSCLC) (Table 3 and Fig. 1).

\section{Afatinib}

Afatinib (BIBW 2992; Boehringer Ingelheim) is an orally bioavailable ErbB Family Blocker that irreversibly blocks signalling from EGFR (ErbB1), HER2 (ErbB2) and ErbB4 [65,66] and also blocks the transphosphorylation of ErbB3; thus blocking all relevant ErbB Family dimers [65].

In vitro and in vivo, afatinib has shown similar potency against the EGFR L858R mutation versus gefitinib and against the HER2 YVMA mutant versus the EGFR/HER2 TKI, lapatinib [65,66]. Moreover, afatinib showed significantly greater activity against the TKIresistant EGFR double mutant, L858R/T790M, than gefitinib. Furthermore, afatinib was more effective than erlotinib, gefitinib, and lapatinib in inhibiting human NSCLC cell lines harbouring wild-type EGFR or the L858R/T790M double mutant. Similarly, in xenograft models of NSCLC, afatinib has suppressed tumour growth to a greater extent than gefitinib or lapatinib and was also effective in xenografts resistant to EGFR TKIs [65]. These preclinical data suggested the potential for afatinib to offer clinical benefit to patients with ErbB Family-driven tumours. Overall afatinib has a low potential for drug-drug interactions [67]. Afatinib is not metabolised but enzyme-catalysed metabolic reactions and is not an inhibitor or an inducer of the CYP enzymes [67]. In vitro studies have shown that afatinib interacts with the drug transport systems involving p-glycoprotein (P-gp) and Phase I studies support the adjustment of afatinib dose as tolerated in patients requiring coadministration of P-gp inhibitors/inducers [67,68]. Afatinib is dosed once daily and should preferably not be taken with food; Phase I studies have shown that when consumed with a high fat meal exposure to afatinib is reduced $[68,69]$.

Afatinib is being investigated in NSCLC in the LUX-Lung clinical trial programme as a first-line treatment in patients with EGFRactivating mutations (LUX-Lung 2, 3, 6 and 7) and as a secondor third-line treatment in patients previously treated with EGFR TKIs (LUX-Lung 1, 4 and 5) [70]. Afatinib is also being assessed in LUX-Lung 8, a Phase III, randomized trial comparing afatinib with

Table 3

Drugs targeting EGFR signalling pathways in NSCLC.

\begin{tabular}{|c|c|}
\hline Agent & Detail \\
\hline Afatinib & $\begin{array}{l}\text { ErbB Family Blocker that irreversibly blocks signalling from EGFR (ErbB1), HER2 } \\
\text { (ErbB2) and ErbB4 tyrosine kinases and transphosphorylation of ErbB3. It is active } \\
\text { against EGFR mutations targeted by erlotinib and gefitinib but also against those } \\
\text { insensitive to these therapies, that is the wild-type and the mutant forms of EGFR and } \\
\text { HER2. }\end{array}$ \\
\hline Cetuximab & $\begin{array}{l}\text { Chimeric monoclonal antibody inhibitor of EGFR was associated with CRs in mice } \\
\text { with tumours harbouring the } T 790 \mathrm{M} \text { mutation or the L858R mutation. Under study in } \\
\text { combination with afatinib. }\end{array}$ \\
\hline Dacomitinib & $\begin{array}{l}\text { Agent with activity against wild-type EGFR, HER2, and ErbB4 and effective against } \\
\text { NSCLC cell lines with deletion of EGFR exon } 19 \text { and L858R mutation and } \\
\text { L858R/T790M mutation. }\end{array}$ \\
\hline Lapatinib & Reversible EGFR/HER2 TKI. It has limited activity in patients with advanced NSCLC. \\
\hline AZD9291 & $\begin{array}{l}\text { Irreversible TKI targeting both EGFR activating and resistance (T790M) mutations. } \\
\text { Limited inhibition in wild-type EGFR. }\end{array}$ \\
\hline CO-1686 & $\begin{array}{l}\text { Irreversible TKI targeting with both EGFR activating and resistance (T790M) } \\
\text { mutations. Limited activity in wild-type EGFR. }\end{array}$ \\
\hline XL647 & $\begin{array}{l}\text { An oral small-molecule inhibitor of multiple receptor tyrosine kinases, including } \\
\text { EGFR, VEGFR2, HER2 and EphB4. }\end{array}$ \\
\hline
\end{tabular}

Pelitinib, AV-412/MP- These are new EGFR tyrosine kinase inhibitors which are under development. 412 and BMS-599626

CR, complete response; EGFR, epidermal growth factor receptor; EphB4, ephrin type-B receptor 4; HER2, human epidermal growth factor receptor 2; NSCLC, non-small-cell lung carcinoma; TKI, tyrosine kinase inhibitor; VEGFR2, vascular endothelial growth factor receptor 2 . 
erlotinib in patients with advanced squamous cell NSCLC, who have progressed after platinum-based chemotherapy. The Phase IIb/III LUX-Lung 1 trial evaluated afatinib versus placebo in patients with NSCLC who had experienced prior treatment failure on reversible EGFR TKIs, gefitinib and/or erlotinib, and one or two lines of chemotherapy [71]. The median PFS was significantly longer $(P<0.0001)$ and response was higher with afatinib (PRs in 29 patients versus one patient) when compared with placebo. Although this did not translate into an OS benefit. The trial did not meet its primary endpoint since not survival benefit was observed with afatinib in the overall population (afatinib 10.8 months versus 12.0 months in the placebo). Interpretation of the lack of benefit in OS during the trial may be complicated by cancer treatments administered post-progression and the fact that afatinib was not the final treatment patients received. Indeed 79\% and $68 \%$ of patients in the placebo and afatinib arms, respectively, received additional treatment. Afatinib treatment in LUX-Lung 1 was also associated with significant improvement in NSCLCrelated symptoms and quality of life ( $Q 0 L ; P \leqslant 0.05$ ) [72]. In the first-line setting, the clinical activity of afatinib was assessed in the proof-of-concept, Phase II LUX-Lung 2 study, which enrolled 129 patients with EGFR-mutation-positive NSCLC (>80\% with Del19 or L858R mutations) [73]; 61 patients received afatinib first-line and 68 patients received afatinib as second-line therapy. Regardless of starting dose (50 mg $(n=99)$ or $40 \mathrm{mg}(n=30)$ ), afatinib demonstrated notable anti-tumour activity in the selected patient population, with two complete responses (CRs) and 77 PRs; thus representing an overall response rate (ORR) of $61 \%$ (independent review). There was no significant difference in achieving an objective response between those who received afatinib treatment first-line (40 [66\%] of 61 ) versus second-line (39 [57\%] of 68 ; odds ratio [OR]: $0.71,95 \%$ confidence interval [CI]: $0.35-$ 1.44) or between those who received afatinib $40 \mathrm{mg}$ as first dose (18 [60\%] of 30) versus $50 \mathrm{mg}$ as first dose (61 [62\%] of 99; OR 1.07, 95\% CI: 0.46-2.47). The subsequent LUX-Lung 3 trial was the largest randomised, global prospective Phase III study of afatinib versus cisplatin/pemetrexed as first-line treatment for patients with advanced adenocarcinoma of the lung harbouring EGFR-activating mutations [74]. The median PFS for afatinib treatment was significantly longer than for cisplatin/pemetrexed in the overall study population and in patients with common EGFR mutations, del19 and L858R. Recent results from LUX-Lung 6, the companion Phase III study to LUX-Lung 3, reinforce the superiority of afatinib over chemotherapy (gemcitabine/cisplatin) alone in the EGFR mutation-positive NSCLC patient population [75]. The safety profile of afatinib has demonstrated consistency across studies; the most frequent adverse events, diarrhoea and rash, were manageable $[76,77]$. On the basis of these key studies, afatinib monotherapy has gained approval for the treatment of EGFR TKI-naïve patients with locally advanced or metastatic NSCLC and activating EGFR mutations. Interestingly, recently a data analysis from LUXLung 2, LUX-Lung 3 and LUX-Lung 6 have shown that afatinib is active in lung tumours harbouring uncommon EGFR mutations, such as G719X, L861Q and S768I [78]. The rate and duration of response was comparable with that previously observed in patients with common mutations in these trials. While the response rate was low in tumours with de novo T790M mutations and insertions in exon 20 durable tumour control was achieved in some patients. In LUX-Lung 3 [78].

Afatinib has also been studied in combination with cetuximab, a chimeric mAb against EGFR. Afatinib plus cetuximab was associated with CRs in mice with tumours harbouring the T790M mutation or the L858R mutation [79,80]. Preliminary results from a Phase I trial of EGFR-mutant NSCLC patients with progressive disease following treatment with erlotinib or gefitinib (NCT01090011) showed disease control in all patients $(n=22)$ treated with afatinib $40 \mathrm{mg}$ plus cetuximab $500 \mathrm{mg} / \mathrm{m}^{2}$ and confirmed PR in 8 patients (36\%) including 4 patients with T790M mutation [81]. These findings are in contrast to negative results from a Phase I/II trial of cetuximab and erlotinib in patients with lung adenocarcinoma and acquired resistance to erlotinib [82].

\section{Dacomitinib}

Dacomitinib (PF-00299804; Pfizer) is active against wild-type EGFR, HER2, and ErbB4. Pre-clinical in vitro and in vivo studies showed activity for dacomitinib against EGFR-sensitising mutations, the EGFR T790M resistance mutation, and wild-type and mutant HER2 [83]. Dacomitinib is metabolised by CYP2D6. Administration of drugs that are highly dependent on CYP2D6 metabolism may require dose adjustment or substitution with an alternative medication. Recent Phase I pharmacokinetic data suggest that dacomitinib exposure may be slightly affected by moderate hepatic impairment [84]. Since many patients with advanced cancer have liver metastases leading to impaired liver function, dose adjustment may be required.

Dacomitinib was clinically active in a two-arm Phase II trial in patients with advanced NSCLC who had failed 1 or 2 prior chemotherapy regimens and prior erlotinib treatment [85]. Other studies provided evidence of additional clinical activity in advanced lung carcinoma [86], versus erlotinib as second- or third-line therapy in patients with advanced NSCLC [87], and in Kirsten rat sarcoma viral oncogene homologue (KRAS) wild-type patients refractory to at least one chemotherapy regimen and erlotinib [88]. Interim results from an ongoing Phase II open label trial (NCT00818441) of dacomitinib showed that $74 \%$ of patients with advanced lung adenocarcinoma and EGFR-activating mutations experienced PR and remained progression-free at 1 year, and that the median PFS was 17 months [89]. Diarrhoea and skin and nail changes were common side effects.

Based on PFS benefits with dacomitinib versus erlotinib in a previous Phase II study of pre-treated patients [90], a randomised, double-blind, Phase III trial (ARCHER 1009) was initiated. The study was designed to compare dacomitinib with erlotinib in locally advanced or metastatic NSCLC after at least one prior chemotherapy regimen in two co-primary populations - all patients and patients with KRAS wild-type NSCLC [91]. Initial results of the study have recently been released and have shown that the study did not meet its primary objective and no significant improvement in PFS was observed in dacomitinib-treated patients versus those who received erlotinib [92]. A second study, BR.26, which is a double-blind placebo controlled randomized Phase III study assessing dacomitinib in patients with incurable stage IIIB/ IV NSCLC after failure of standard therapy for advanced or metastatic disease has also recently release of initial findings. The study did not meet its objective of prolonging OS versus placebo [92]. A third study, ARCHER 1050, is ongoing and will assess dacomitinib versus gefitinib in treatment-naïve patients with EGFR-mutant advanced NSCLC. The results are expected in 2015 [92].

\section{Other agents in development}

Several new agents which target the ErbB Family and their signalling pathways are in development. Most recently these include AZD9291 and CO-1686. AZD9291 is an irreversible selective tyrosine kinase inhibitor that targets both EGFR activating and resistance (T790M) mutations. Preclinical work has demonstrated that AZD9291 potently inhibits EGFR phosphorylation across a number of in vitro cell lines harbouring EGFR-mutations including T790M [93]. While in vivo AZD9291 treatment has been associated with profound growth regression across multiple EGFR mutation-positive (PC9; 250\% growth inhibition) and EGFR mutation and T790M positive (H1975; 132\% growth inhibition) tumour models [93]. Tumour growth inhibition was associated with 
profound inhibition of EGFR activity and key downstream signaling pathways and chronic long-term treatment of these xenograft tumours with AZD9291 led to a complete and sustained macroscopic response [93]. Preliminary data from a Phase I dose-escalation study in patients with advanced NSCLC who have progressed following EGFR TKI treatment $(n=18$ plus T790M expansion cohorts $[n=9])$ are encouraging with reports of about $50 \%$ Response Evaluation Criteria in Solid Tumours (RECIST) responses, at the starting dose level of $20 \mathrm{mg}$ once daily ( $n=2$ confirmed partial responses in T790M mutation-positive patients) with good tolerability $[93,94]$.

CO-1686 is an irreversible TKI that also targets EGFR activating and resistance (T790M) mutations. Preclinical work has demonstrated that oral administration of CO-1686 as single agent induces tumour regression in EGFR-mutated NSCLC tumour xenograft and transgenic models [95]. No inhibition of wild-type EGFR is observed. Interestingly in NSCLC cells with acquired resistance to CO-1686 in vitro, there was no evidence of additional mutations or amplification of the EGFR gene, but resistant cells exhibited signs of epithelial-mesenchymal transition and demonstrated increased sensitivity to AKT inhibitors. Initial reports from a Phase I dose-finding study are encouraging with CO-1686 demonstrating good tolerability and efficacy against proven T790M positive EGFR mutant NSCLC, with reports of about $67 \%$ responses, and a strong suggestion of a dose-response relationship [96].

XL647 is an oral small-molecule inhibitor of multiple RTKs, including EGFR, VEGFR2, HER2 and ephrin type-B receptor 4 (EphB4). XL647, administered in an intermittent or daily-dosing schedule, exhibited antitumour activity with an objective response rate (ORR) of 3\% in TKI-resistant patients selected for EGFR-activating mutations [97]. The EGFR-driven component of NSCLC combined with resistance likely precludes the prolonged use of reversible or weak irreversible inhibitors in NSCLC. Neratinib, an EGFR and HER2 TKI, failed to produce a response in advanced NSCLC patients bearing the TKI-resistant T790M mutation. Even maximally tolerated doses of neratinib may be insufficient to prevent potential development of EGFR T790M. To overcome secondary acquired resistance to current quinazoline-derived EGFR TKIs, novel non-quinazoline EGFR inhibitors have been developed to specifically target T790M. Such agents have shown a powerful selective inhibition in vitro against EGFR T790M [98]. The EGFR TKI, icotinib hydrochloride (BPI-2009H), is being tested in preclinical studies, and has shown a significant effect $[99,100]$. Other new EGFR-targeted agents under development include the irreversible TKIs, pelitinib (EKB-569; EGFR, HER2, and ErbB4) and AV-412/ MP-412 (EGFR and HER2), and BMS-599626, a reversible TKI (EGFR/HER2) [101,102].

\section{Agents acting on alternative signalling pathways}

Agents acting on other signalling pathways that complement the EGFR pathway are also being evaluated in clinical trials of advanced NSCLC (Table 4).

\section{MET inhibitors}

MET inhibitors are able to overcome EGFR TKI resistance. Even though specific studies of MET inhibitors for EGFR resistant have not been conducted yet, some evidence has emerged concerning the concomitant inhibition of MET and EGFR pathway. However the positive, encouraging results, reported in the phase II trials $[103,104]$, were not confirmed in the subsequent, phase III studies. The phase III, MET Lung study (NCT01456325), of MET-inhibitor Onartuzumab (MetMAb) plus Erlotinib versus placebo plus Erlotinib, in previously treated, MET-positive, advanced NSCLC, was stopped, following an interim analysis that suggested a lack of clinically meaningful efficacy. A second phase III study exploring onartuzumab plus erolotinib in patients with MET/EGFR-positive advanced NSCLC (NCT02031744) is currently ongoing. Two randomized, phase III trials, MARQUEE and ATTENTION trials, comparing tivantinib plus erlotinib versus placebo plus erlotinib in nonsquamous NSCLC, failed to meet their primary endpoint of OS. However, the secondary endpoint of PFS was significantly extended in favour of tivantinib combinations [105].

\section{Anti-IGF-1R antibodies}

There is a close relationship between the signalling of IGF-1R and EGFR, which supposes activation of the IGF-1R pathway when

Table 4

Drugs inhibiting alternative signalling pathways.

\begin{tabular}{ll}
\hline Agent & Detail \\
\hline Anti-IGFR antibodies & \\
\hline Figitumumab & $\begin{array}{l}\text { Has shown activity in a phase II trial with previously untreated patients } \\
\text { and those with advanced NSCLC who received paclitaxel/carboplatin } \\
\text { with or without figitumumab }\end{array}$ \\
$\begin{array}{ll}\text { R1507 } & \text { Binds to the extracellular domain of IGF-1R with high selectivity and } \\
\text { inhibits receptor activation and function. It has been previously tested in } & \text { some pre-clinical models, demonstrating anticancer activity in some } \\
\text { cancers, including NSCLC }\end{array}$ \\
$\begin{array}{ll}\text { Heave been shown to be suppressors of the EGFR-mediated signalling in } \\
\text { erlotinib-sensitive and erlotinib-resistant cell lines. }\end{array}$ \\
\hline mTOR inhibitors & $\begin{array}{l}\text { Everolimus, produced objective responses in } 7.1 \% \text { of NSCLC patients } \\
\text { who had previously failed chemotherapy and in } 2.3 \% \text { of patients who } \\
\text { had failed chemotherapy and an EGFR TKI }\end{array}$ \\
\hline OARP inhibitors & $\begin{array}{l}\text { Olaparib, combined with gefitinib is being compared with gefitinib } \\
\text { monotherapy in patients with NSCLC bearing EGFR mutations by the } \\
\text { Spanish Lung Cancer Group }\end{array}$ \\
\hline Oestrogen receptor antagonists & The combination of fulvestrant with gefitinib resulted in greater inhibition \\
of growth in cell cultures and xenograft models of NSCLC
\end{tabular}

ALK, anaplastic lymphoma kinase; ATP, adenosine triphosphate; EGFR, epidermal growth factor receptor; HSP90, heat shock protein 90; IGF-1R, insulin-like growth factor 1 receptor; MET, mesenchymal-epithelial transition factor; mTOR, mammalian target of rapamycin; PARP, poly (ADP-ribose) polymerase; TKI, tyrosine kinase inhibitor. 
EGFR is inhibited and the consequent increase in tumour cellular proliferation.

Figitumumab (CP-751,871; Pfizer) is a mAb targeted against IGF-1R [106]. In a Phase II trial of treatment-naïve or advanced NSCLC patients who received paclitaxel/carboplatin with or without figitumumab, RR was $54 \%$ versus $42 \%$ in the chemotherapy alone arm [107]. The addition of figitumumab to chemotherapy also improved PFS, compared with chemotherapy alone. However, patient enrollment in a Phase III clinical trial testing figitumumab plus paclitaxel/carboplatin was halted due to lack of efficacy.

Another $\mathrm{mAb}$ against IGF-1R is R1507. A Phase II trial randomly assigned patients with advanced-stage NSCLC who progressed following one or two prior regimens to receive erlotinib $(150 \mathrm{mg}$ orally once a day) in combination with either placebo, R1507 $9 \mathrm{mg} / \mathrm{kg}$ weekly, or R1507 $16 \mathrm{mg} / \mathrm{kg}$ intravenously once every 3 weeks [108]. The combination of R1507 with erlotinib did not confer a survival advantage over erlotinib alone in an unselected group of patients with advanced NSCLC [108].

\section{Heat shock protein - HSP9O inhibitors}

The heat shock protein (HSP)90 chaperone mediates conformational changes in the ErbB Family, MET, and various downstream kinases, including Akt. Therefore, inhibiting the action of HSP90 is a potentially viable treatment strategy given that EGFR mutations associated with resistance to EGFR TKIs do not compromise the ability of HSP90 to regulate ErbB Family members [109]. Moreover, HSP90 inhibitors have been described as suppressors of EGFR-mediated signalling in erlotinib-sensitive and erlotinib-resistant cell lines [109]. More recently preclinical work with the HSP90 agent, CH5164840, has demonstrated potent antitumour activity and is highly effective in combination with erlotinib against NSCLC tumours with EGFR overexpression and mutations [110]. These findings have been translated into the clinical setting where a Phase II study has recently reported interim data from 16 NSCLC EGFR mutation-positive patients who had progressed on EGFRTKIs who were treated with the HSP90 inhibitor, AUY922, in combination with erlotinib. The ORR was $13 \%$ (2/16; both patients were T790M positive. Four other patients have stable disease for at least 8 weeks [111]. Another phase II study was conducted in patients with previously treated, advanced NSCLC, stratified by molecular status. Interestingly, clinical activity of AUY922 was mainly observed in patients with ALK-positive and EGFR-mutant NSCLC, reporting a $18 \%$ of $R R$, and an estimated $34 \%$ of median PFS rate in the latter subgroup of patients [112].

\section{mTOR inhibitors}

Another pathway of interest in NSCLC is the Akt/mTOR, which is activated by mutant HER2. In a preclinical HER2-driven transgenic murine lung cancer model, synergistic anti-tumour activity was observed with the combination of a HER family inhibitor and an mTOR inhibitor compared with either drug alone [113]. The mTOR inhibitor, everolimus was evaluated in a Phase II trial of patients with advanced NSCLC after one or two previous chemotherapy regimens or chemotherapy plus an EGFR TKI [114]. Everolimus achieved objective responses in $7.1 \%$ of patients who had previously failed chemotherapy, and in $2.3 \%$ of patients who had failed chemotherapy and an EGFR-TKI. A Phase I/II trial evaluated everolimus plus erlotinib versus erlotinib alone in patients with advanced NSCLC who progressed after more than two previous lines of chemotherapy, showing an improved disease control rate (DCR) [115].

\section{PARP inhibitors}

Poly adenosine diphosphate (ADP)-ribose polymerases (PARPs) are a family of nuclear enzymes that play a critical role in cellular processing of DNA damage through the base excision repair pathway. PARP inhibition can be directly cytotoxic to tumour cells, thus agents targeting PARP could be suitable for enhancing radio/ chemotherapy and overcoming drug resistance [116]. A large, multicentre, prospective study, conducted by the Spanish Lung Cancer Group, will evaluate the clinical efficacy and safety profile of olaparib, a potent, orally active, PARP inhibitor, plus gefitinib versus gefitinib monotherapy in patients with NSCLC bearing EGFR mutations (NCT01513174).

\section{Controlling oestrogens}

The oestrogen receptor (ER) beta has been detected in NSCLC cells [117]. In fact, ERs are expressed independently of gender and histology [118] and oestrogens stimulate growth of NSCLC cells and tumour xenografts [118,119]. EGFR and ER pathways share signalling molecules; thus, activation of EGFR results in activation of ERs. Studies in cell cultures and xenographic models have shown that the combination of the ER antagonist, fulvestrant and gefitinib resulted in an additional inhibition of growth $[118,120]$. In an analysis of 317 NSCLC tumours it has been shown that oestrogen receptor $\alpha$ and $\beta$ expression distinguishes a subset of NSCLC that has defined clinicopathologic and genetic features. Indeed data from this study demonstrated a positive correlation between oestrogen receptor $\alpha$ expression and EGFR mutations in lung adenocarcinoma [121]. A recent study has suggested that lung cancer in female never-smokers is frequently associated with an EGFR mutation and ER $\alpha$ expression, with a correlation between both markers. These findings suggest the possibility of treating this population by targeting both hormonal factors and genetic abnormalities [122]. Several Phase II trials are evaluating the hypothesis that the combination of fulvestrant and an EGFR inhibitor, such as erlotinib [118,119] or gefitinib [117] will provide improved efficacy over the EGFR inhibitor alone in NSCLC patients.

\section{HDAC inhibitors}

In vitro studies have demonstrated that gefitinib resistant cell lines were simultaneously treated with the histone deacetylase (HDAC) inhibitor vorinostat and gefitinib a synergistic effect was observed in four out of five of the cell lines tested [123]. These data suggest that HDAC inhibitors overcome EGFR-TKI resistance. It is postulated that this is achieved by the upregulation of E-cadherin expression which facilitates synergy between the HDAC and EGFR-TKI. There may also be a role of ErbB3 in this process [123]. Another study has recently shown that the HDAC inhibitor Vorinostat increased expression of the pro-apoptotic $\mathrm{BH} 3$ domain-containing the isoform of BIM, epigenetically restoring BIM function and EGFR-TKI sensitivity, in EGFR-mutant NSCLC, where resistance to TKI is associated with BIM polymorphism [124]. However, the effectiveness of this treatment strategy in overcoming EGFR-TKI acquired resistance, remains to be proven in clinical setting. In a phase I/II trial, the combination of Erlotinib and Vorinostat has shown no magniful activity in NSCLC patients with EGFR mutations, after Erlotinib progression [125]. The results of another randomized Phase II study have shown that patients with advanced NSCLC, who have progressed on erlotinib, who also have elevated E-cadherin, have a better outcome when treated with erlotinib plus entinostat (OS $=9.4$ months), another HDAC inhibitor, versus erlotinib alone (OS $=5.4$ months) [126].

\section{Novel treatment paradigms}

The move towards targeted therapy also requires changes to existing treatment approaches. 
Accelerated progression after EGFR TKI discontinuation in patients with acquired resistance

An accelerated progression of disease in patients with EGFRmutant lung cancer and acquired resistance to erlotinib or gefitinib after discontinuation of reversible EGFR TKI therapy has been observed. The first description of this phenomenon was published by Riely et al. in a prospective assessment of discontinuation and reinitiation of erlotinib or gefitinib in patients with acquired resistance to these agents [127]. The study recommended implementation of a randomised trial to assess the value of continuing erlotinib or gefitinib after development of acquired resistance [127]. More recently, Chaft et al. evaluated disease progression in patients with EGFR-mutant lung cancer with acquired resistance who needed to discontinue EGFR TKI [128]. In 40 of 61 patients (95\% CI, 14-35), accelerated progression was observed and was associated with shorter time to progression on initial TKI $(P=0.002)$ and the presence of pleural $(P=0.03)$ or central nervous system $(\mathrm{CNS})$ disease $(P=0.01)$. No association with the presence of $7790 \mathrm{M}$ at the time of acquired resistance was found. These results suggest that washout periods must be minimised in these patients [128].

\section{Continued treatment post-progression with EGFR TKI}

EGFR TKI treatment should normally stop when disease progression is confirmed, even though treatment discontinuation is usually followed by an acute exacerbation of the disease. In certain conditions, continuous administration of EGFR TKI following disease progression appears to be a valid treatment option $[129,130]$ as it can be suggested that tumour cell populations remain sensitive to EGFR TKIs after progression. Therefore, postprogression EGFR TKI treatment combined with chemotherapy is plausible, and early indications suggest that the choice of chemotherapy will depend on avoiding intolerable adverse events due to the amplified toxicity of the combination. Two randomized, phase III trials, PREFER and IMPRESS (NCT01544179), are currently investigating the effectiveness of continuing EGFR TKI, Erlotinib or Gefitinib, after progression on first-line TKI treatment, combined with platinum based chemotherapy versus chemotherapy alone of note, new agents which target the ErbB Family are also being investigated in combination with chemotherapy beyond progression. The second part of the LUX-Lung 5, phase III, randomized study, aims to investigate the use of afatinib with chemotherapy in patients who progress on afatinib alone. In this study patients have previously been treated with erlotinib/gefitinib and therefore highly selected for the presence of EGFR mutations [131]. Further investigation will determine the effectiveness of such combination therapy, but there is evidence to suggest that the tumour genotype and phenotype may evolve dynamically under the selective pressure of TKI therapies considering that genetic mechanisms of resistance are lost in the absence of the continued selective pressure of the EGFR inhibitor treatment. Hence, in order to know how best to prevent or overcome resistance to treatment, there is a need for continuing assessment of the genotypic and histological evolution of the cancer over the course of therapy in each patient.

\section{Re-treatment with EGFR TKIs after having completed treatment with} EGFR TKIs

Conventional chemotherapy is usually considered the only option for patients who progress following an initial response to EGFR TKIs. However, it has been observed that some NSCLC cell lines are able to regain sensitivity to TKIs [37], which suggests the action of a non-mutational and reversible EGFR TKI drug resistance mechanism. In a retrospective study of patients with stage IV
NSCLC who progressed after previously achieving long term disease control on EGFR TKI treatment, subsequent treatment with standard chemotherapy and, at renewed progression, retreatment with erlotinib (alone or in combination with cetuximab) was considered a viable option [132]. Several evidences support the retreatment with the same [133-137], or different [138-143] EGFR-TKI in patients who showed SD during 1st TKI treatment, while lower activity is reported for those patients who had PD to 1st TKI [144]. The highly heterogeneous nature of NSCLC tumours with respect to the mutations causing both the initial tumour and treatment response, which can also change in response to treatment, can create an apparent paradox whereby failure of a treatment at one stage of the disease does not mean that the same treatment might not be beneficial at a later stage. Intratumoural heterogeneity is therefore a subject of interest, and its importance in the development of biomarker strategies and drug development is increasingly recognised.

\section{Approaches based on different growth rate of resistant cells lines to} EGFR TKIs

Most advanced NSCLCs with activating EGFR mutations respond initially to EGFR TKIs. Chmielecki et al. theorised that the current dosing schedules of gefitinib and erlotinib, created to target wildtype EGFR, were not optimised for resistant EGFR [145]. In order to investigate this further, isogenic TKI-sensitive and TKI-resistant pairs of cell lines were developed to replicate the behaviour of human tumours. Observations that the drug-resistant EGFRmutant cells exhibited a slower growth were used to create evolutionary mathematical cancer models, which were able to predict alternative therapeutic strategies to prolong the clinical benefit of TKIs against EGFR-mutant NSCLCs, by delaying the development of resistance [145]. These models predicted that high-dose pulses with low-dose continuous therapy were likely to be the most effective in preventing the development of resistance [146].

\section{Combining radiotherapy with EGFR TKIs in patients with brain metastases}

Brain metastases are a common and devastating consequence of disease progression in patients with NSCLC. The administration of radiotherapy to control brain metastases has proven survival benefit [147]. Several studies using growth factor inhibitors to modify tumour proliferation and/or radiosensitivity, report the potential to improve tumour control [148]. Combining first-line erlotinib/ gefitinib with early multi-target radiotherapy is very effective in selected patients who respond to TKI, when the status of EGFR mutations is unknown before treatment [149]. In another study, the presence of EGFR mutations and the administration of EGFR TKI during radiotherapy independently conferred radiosensitivity in brain metastases of lung adenocarcinoma, with the best response rate achieved in the subgroup of patients who received TKI during radiotherapy [147]. Furthermore, experimental models show that gefitinib could inhibit cellular proliferation and enhance tumour response to radiation [147]. To summarise, continuous administration of EGFR TKI during and following radiotherapy for progressive disease in brain metastases appears to be a potential treatment option [129] but further work is needed to fully assess the use of this approach.

\section{Use of local ablative therapy for oligoprogressive disease with continued TKI treatment}

Disease progression is often observed at limited sites in patients with EGFR mutation-positive NSCLC. It is now postulated that there is a role for local ablative therapy (LAT) in patients with 
CNS and/or limited systemic disease progression. In many cases disease progression is due to the treatment not penetrating the CNS. Consequently, it is unlikely that a patient will have developed systemic resistance to a drug and may be deriving significant ongoing benefit from its use [150]. This idea is based on reports in the literature of the benefit of radiation therapy on isolated CNS progression in patients with EGFR mutant NSCLC being treated with EGFR TKIs who also received continued systemic administration of the TKI in the absence of systemic progression [129]. A recent study has extended the use of LAT to those NSCLC patients with limited systemic disease progression or 'oligoprogressive disease' [150]. The authors of this study hypothesised that treatment of systemic progression before resistant clones can be spread will allow disease control to be achieved until the resistant clones can multiply and become detectable. In addition, there is also the theory that other, non-progressing sites, will benefit from targeted therapy due to continued suppression of sensitive clones that have not yet developed acquired resistance [150]. In patients with metastatic anaplastic lymphoma kinase (ALK)+ NSCLC treated with crizotinib $(n=38)$ and EGFR-MT NSCLC treated with erlotinib ( $n=27)$ a subset $(n=25 / 51)$ with either non-leptomeningeal CNS and/or $\leqslant 4$ sites of extra-CNS progression (oligoprogressive disease) suitable for LAT received either radiation $(n=24)$ or surgery $(n=1)$ to these sites and continued on the same TKI. After LAT 19/25 patients progressed again, with median PFS of 6.2 months [150].

\section{Combining chemotherapy with TKIs}

Several randomized trials have shown no significant improvement of survival by combining EGFR-TKIs and chemotherapy in a population unselected for EGFR [15,7,151,8,152,153].

However, one of the such trials, the CALGB30406, reported evidence to suggest that EGFR mutations identify patients most likely to benefit [15]. More recently, the FASTACT2 trial demonstrated that intercalated chemotherapy and erlotinib is a viable first-line option for patients with non-small-cell lung cancer with EGFR mutation-positive disease or selected patients with unknown EGFR mutation status [154]. Survival outcomes were significantly prolonged with intercalated combination, leading a median PFS of 16.8 months and a median OS of 31.4 months, only in patients with an activating EGFR gene mutation [154]. These results are similar to those reported in phase 3 trials of single-agent EGFR TKIs in east Asian [155] and European populations [17,156] Therefore the current debate is: will the intercalated strategy ultimately delay or prevent the onset of acquired resistance? Which are the mechanism of how a TKI intercalated with chemotherapy might delay the onset of acquired resistance? The best schedule (timing, sequence, ...) of TKI and chemotherapy is still unknown. Further randomised studies are needed, to compare the new intercalated approach versus TKI alone followed by chemotherapy treatment, which remains the standard of care in this subgroup of patients.

\section{Conclusions}

The treatment of NSCLC with reversible EGFR TKIs is limited by the development of acquired resistance. The aetiology of resistance to EGFR TKIs is most often caused by mutations in the EGFR gene most commonly T790M - but also attributed to MET or HGF, EMT cell transformations, phenotypic change from NSCLC to SCLC and signalling pathway changes. Modifications in parallel signalling pathways, such as the amplification of the CRKL oncogene have also been considered as inducers of resistance effects in NSCLC. It is clear that the blockade of each of these alterations could have therapeutic potential. The search for pathways to overcome the resistance to EGFR TKIs has been a focus of research in recent years with several potentially useful agents currently under development. The most clinically advanced agent in development is the ErbB Family Blocker, afatinib, which has shown encouraging results in several trials, and has received approval as monotherapy for the treatment of EGFR TKI-naïve patients with locally advanced or metastatic NSCLC and activating EGFR mutations. Promising results emerged from early phase I studies, investigating the safety and activity of a new class of non-quinazoline, EGFR inhibitors, that also target EGFR activating and resistance (T790M) mutations. Another possibility is the use of inhibitors of parallel signalling pathways, such as MET, HSP90, mTOR, PARP inhibitors or antiIGF-1R mAbs. The regulation of the oestrogen receptor with fulvestrant is also a therapeutic option, in combination with EGFR TKIs.

As drug resistance appears to be pleomorphic, changes to standard treatment approaches, including different schedules and combinations, may also be an effective strategy in circumventing resistance. However, appropriate pharmacological evaluation should always be accompanied by a deeper understanding of the genetic alterations of tumour cells and of tumour heterogeneity, emphasising the need for continuous monitoring of the tumour genotype by both rebiopsy or liquid biopsy in order to lead decision-making. The evaluation of resistance development should also be carried out, because the standard definition of disease progression according to RECIST criteria has not always been related to clinical worsening during EGFR TKI treatment.

\section{Declaration of interest}

The authors state no conflict of interest and have received no payment in preparation of this manuscript.

\section{References}

[1] Bronte G, Rizzo S, La Paglia L, Adamo V, Siragusa S, Ficorella C, et al. Driver mutations and differential sensitivity to targeted therapies: a new approach to the treatment of lung adenocarcinoma. Cancer Treat Rev 2010;36(Suppl. 3):S21-9. http://dx.doi.org/10.1016/S0305-7372(10)70016-5. PMID: 21129606.

[2] Ayoola A, Barochia A, Belani K, Belani CP. Primary and acquired resistance to epidermal growth factor receptor tyrosine kinase inhibitors in non-small cell lung cancer: an update. Cancer Invests 2012;30(5):433-46. http://dx.doi.org 10.3109/07357907.2012.666691. PMID: 22571344.

[3] Fukuoka M, Yano S, Giaccone G, Tamura T, Nakagawa K, Douillard JY, et al. Multi-institutional randomized phase II trial of gefitinib for previously treated patients with advanced non-small-cell lung cancer (The IDEAL 1 Trial) [corrected]. J Clin Oncol 2003; 21(12): 2237-46. [Epub 2003 May 14. Erratum in J Clin Oncol 2004; 22(23):4863].

[4] Kris MG, Natale RB, Herbst RS, Lynch Jr TJ, Prager D, Belani CP, et al. Efficacy of gefitinib, an inhibitor of the epidermal growth factor receptor tyrosine kinase in symptomatic patients with non-small cell lung cancer: a randomized trial. JAMA 2003;290(16):2149-58.

[5] Pérez-Soler R, Chachoua A, Hammond LA, Rowinsky EK, Huberman M, Karp D et al. Determinants of tumor response and survival with erlotinib in patients with non-small-cell lung cancer. J Clin Oncol 2004;22(16):3238-47.

[6] Shepherd FA, Rodrigues Pereira J, Ciuleanu T, Tan EH, Hirsh V, Thongprasert S, et al. Erlotinib in previously treated non-small-cell lung cancer. N Engl J Med 2005;353(2):123-32.

[7] Giaccone G, Herbst RS, Manegold C, Scagliotti G, Rosell R, Miller V, et al Gefitinib in combination with gemcitabine and cisplatin in advanced nonsmall-cell lung cancer: a phase III trial - INTACT 1. J Clin Oncol 2004;22(5):777-84.

[8] Herbst RS, Prager D, Hermann R, Fehrenbacher L, Johnson BE, Sandler A, et al. TRIBUTE Investigator Group. TRIBUTE: a phase III trial of erlotinib hydrochloride (OSI-774) combined with carboplatin and paclitaxel chemotherapy in advanced non-small-cell lung cancer. J Clin Oncol 2005;23(25):5892-9 [Epub 2005 July 25]

[9] Thatcher N, Chang A, Parikh P, Rodrigues Pereira J, Ciuleanu T, von Pawel J, et al. Gefitinib plus best supportive care in previously treated patients with refractory advanced non-small-cell lung cancer: results from a randomised, placebo-controlled, multicentre study (Iressa Survival Evaluation in Lung Cancer). Lancet 2005;366(9496):1527-37.

[10] Mok TS, Wu YL, Thongprasert S, Yang CH, Chu DT, Saijo N, et al. Gefitinib or carboplatin-paclitaxel in pulmonary adenocarcinoma. $\mathrm{N}$ Engl J Med 2009;361(10):947-57. http://dx.doi.org/10.1056/NE]Moa0810699 [Epub 2009 August 19]. 
[11] Maemondo M, Inoue A, Kobayashi K, Sugawara S, Oizumi S, Isobe H, et al Gefitinib or chemotherapy for non-small-cell lung cancer with mutated EGFR. N Engl J Med 2010;362(25):2380-8 [Epub 2010/06/25].

[12] Mitsudomi T, Morita S, Yatabe Y, Negoro S, Okamoto I, Tsurutani J, et al. Gefitinib versus cisplatin plus docetaxel in patients with non-small-cell lung cancer harbouring mutations of the epidermal growth factor receptor (WJTOG3405): an open label, randomised phase 3 trial. Lancet Oncol 2010;11(2):121-8 [Epub 2009/12/22].

[13] Gridelli C, De Marinis F, Di Maio M, Cortinovis D, Cappuzzo F, Mok T. Gefitinib as first-line treatment for patients with advanced non-small-cell lung cancer with activating epidermal growth factor receptor mutation: review of the evidence. Lung Cancer 2011;71(3):249-57 [Epub 2011/01/11].

[14] Zhou C, Wu YL, Chen G, Feng J, Liu XQ, Wang C, et al. Erlotinib versus chemotherapy as first-line treatment for patients with advanced EGFR mutation-positive non-small-cell lung cancer (OPTIMAL, CTONG-0802): multicentre, open-label, randomised, phase 3 study. Lancet Oncol 2011;12(8):735-42 [Epub 2011/07/26].

[15] Janne PA, Wang X, Socinski MA, Crawford J, Stinchcombe TE, Gu L, et al. Randomized phase II trial of erlotinib alone or with carboplatin and paclitaxel in patients who were never or light former smokers with advanced lung adenocarcinoma: CALGB 30406 trial. J Clin Oncol 2012;30(17):2063-9 [Epub 2012/05/02]

[16] Janne P, Wang X, Socinski M, Crawford J, Capelletti M, Edelman M, et al. Randomized phase II trial of erlotinib (E) alone or in combination with carboplatin/paclitaxel (CP) in never or light former smokers with advanced lung adenocarcinoma: CALGB 30406. J Clin Oncol 2012;30(17):2063-9. http://dx.doi.org/10.1200/JCO.2011.40.1315 [Epub 2012 April 30].

[17] Rosell R, Carcereny E, Gervais R, Vergnenegre A, Massuti B, Felip E, et al. Erlotinib versus standard chemotherapy as first-line treatment for European patients with advanced EGFR mutation-positive non-small-cell lung cancer (EURTAC): a multicentre, open-label, randomised phase 3 trial. Lancet Oncol 2012;13(3):239-46 [Epub 2012/01/31].

[18] Santamaria I, Menendez ST, Balbin M. EGFR L858R mutation may go undetected because of $\mathrm{P} 848 \mathrm{~L}$ in cis mutation. J Clin Oncol 2013;31(26):e420-1 [Epub 2013/07/31].

[19] Paez JG, Janne PA, Lee JC, Tracy S, Greulich H, Gabriel S, et al. EGFR mutations in lung cancer: correlation with clinical response to gefitinib therapy. Science 2004;304(5676):1497-500 [Epub 2004/05/01].

[20] Kosaka T, Yatabe Y, Endoh H, Kuwano H, Takahashi T, Mitsudomi T. Mutations of the epidermal growth factor receptor gene in lung cancer: biological and clinical implications. Cancer Res 2004;64(24):8919-23 [Epub 2004/12/18].

[21] Sharma SV, Bell DW, Settleman J, Haber DA. Epidermal growth factor receptor mutations in lung cancer. Nat Rev Cancer 2007;7(3):169-81 [Epub 2007/02 24].

[22] Jackman D, Pao W, Riely GJ, Engelman JA, Kris MG, Janne PA, et al. Clinical definition of acquired resistance to epidermal growth factor receptor tyrosine kinase inhibitors in non-small-cell lung cancer. J Clin Oncol 2010;28(2):357-60 [Epub 2009/12/02].

[23] Bronte G, Rolfo C, Giovannetti E, Cicero G, Pauwels P, Passiglia F, et al. Are erlotinib and gefitinib interchangeable, opposite or complementary for nonsmall cell lung cancer treatment? Biological, pharmacological and clinical aspects. Crit Rev Oncol Hematol 2014;89(2):300-13. http://dx.doi.org/ 10.1016/i.critrevonc.2013.08.003 [Epub 2013 August 28].

[24] Fujita Y, Suda K, Kimura H, Matsumoto K, Arao T, Nagai T, et al. Highly sensitive detection of EGFR T790M mutation using colony hybridization predicts favorable prognosis of patients with lung cancer harboring activating EGFR mutation. J Thorac Oncol 2012;7(11):1640-4 [Epub 2012/08/18].

[25] Rosell R, Molina MA, Costa C, Simonetti S, Gimenez-Capitan A, Bertran-Alamillo J, et al. Pretreatment EGFR T790M mutation and BRCA1 mRNA expression in erlotinib-treated advanced non-small-cell lung cancer patients with EGFR mutations. Clin Cancer Res 2011;17(5):1160-8 [Epub 2011/01/15].

[26] Inukai M, Toyooka S, Ito S, Asano H, Ichihara S, Soh J, et al. Presence of epidermal growth factor receptor gene T790M mutation as a minor clone in non-small cell lung cancer. Cancer Res 2006;66(16):7854-8 [Epub 2006/08 17].

[27] Su KY, Chen HY, Li KC, Kuo ML, Yang JC, Chan WK, et al. Pretreatment epidermal growth factor receptor (EGFR) T790M mutation predicts shorter EGFR tyrosine kinase inhibitor response duration in patients with non-smallcell lung cancer. J Clin Oncol 2012;30(4):433-40 [Epub 2012/01/05].

[28] Oxnard GR, Janjigian YY, Arcila ME, Sima CS, Kass SL, Riely GJ, et al. Maintained sensitivity to EGFR tyrosine kinase inhibitors in EGFR-mutan lung cancer recurring after adjuvant erlotinib or gefitinib. Clin Cancer Res 2011;17(19):6322-8 [Epub 2011/08/13].

[29] Costa C, Molina MA, Drozdowskyj A, Gimenez-Capitan A, Bertran-Alamillo J, Karachaliou N, et al. The impact of EGFR T790M mutations and BIM mRNA expression on outcome in patients with EGFR-mutant NSCLC treated with erlotinib or chemotherapy in the randomized phase III EURTAC trial. Clin Cancer Res 2014;20(7):2001-10 [Epub 2014/02/05].

[30] Santarpia M, Magri I, Sanchez-Ronco M, Costa C, Molina-Vila MA, GimenezCapitan A, et al. MRNA expression levels and genetic status of genes involved in the EGFR and NF-kappaB pathways in metastatic non-small-cell lung cancer patients. J Transl Med 2011:9:163 [Epub 2011/09/29].

[31] Bivona TG, Hieronymus H, Parker J, Chang K, Taron M, Rosell R, et al. FAS and NF-kappaB signalling modulate dependence of lung cancers on mutant EGFR. Nature 2011;471(7339):523-6 [Epub 2011/03/25].
[32] Faber AC, Corcoran RB, Ebi H, Sequist LV, Waltman BA, Chung E, et al. BIM expression in treatment-naive cancers predicts responsiveness to kinase inhibitors. Cancer discovery. 2011;1(4):352-65. [Epub 2011/12/07].

[33] Costa C, Molina MA, Drozdowskyj A, Gimenez-Capitan A, Bertran-Alamillo J, Karachaliou N, et al. The Impact of EGFR T790M Mutations and BIM mRNA Expression on Outcome in Patients with EGFR-Mutant NSCLC Treated with Erlotinib or Chemotherapy in the Randomized Phase III EURTAC Trial. Clin Cancer Res. 2014. Epub 2014/02/05. Clin Cancer Res. 2014 Apr 1;20(7), pp. 2001-10. http://dx.doi.org/10.1158/1078-0432.CCR-13-2233. [Epub 2014 Feb 3].

[34] Ng KP, Hillmer AM, Chuah CT, Juan WC, Ko TK, Teo AS, et al. A common BIM deletion polymorphism mediates intrinsic resistance and inferior responses to tyrosine kinase inhibitors in cancer. Nat Med 2012;18(4):521-8 [Epub 2012/03/20].

[35] Nakagawa T, Takeuchi S, Yamada T, Ebi H, Sano T, Nanjo S, et al. EGFR-TKI resistance due to BIM polymorphism can be circumvented in combination with HDAC inhibition. Cancer Res 2013;73(8):2428-34 [Epub 2013/02/06].

[36] Kobayashi S, Boggon TJ, Dayaram T, Janne PA, Kocher O, Meyerson M, et al. EGFR mutation and resistance of non-small-cell lung cancer to gefitinib. N Engl J Med 2005;352(8):786-92 [Epub 2005/02/25].

[37] Sharma SV, Lee DY, Li B, Quinlan MP, Takahashi F, Maheswaran S, et al. A chromatin-mediated reversible drug-tolerant state in cancer cell subpopulations. Cell 2010;141(1):69-80 [Epub 2010/04/08].

[38] Suda K, Onozato R, Yatabe Y, Mitsudomi T. EGFR T790M mutation: a double role in lung cancer cell survival? J Thorac Oncol 2009;4(1):1-4 [Epub 2008/ $12 / 20]$.

[39] Balak MN, Gong Y, Riely GJ, Somwar R, Li AR, Zakowski MF, et al. Novel D761Y and common secondary T790M mutations in epidermal growth factor receptor-mutant lung adenocarcinomas with acquired resistance to kinase inhibitors. Clin Cancer Res 2006;12(21):6494-501 [Epub 2006/11/07].

[40] Engelman JA, Zejnullahu K, Mitsudomi T, Song Y, Hyland C, Park JO, et al. MET amplification leads to gefitinib resistance in lung cancer by activating ERBB3 signaling. Science 2007;316(5827):1039-43 [Epub 2007/04/2].

[41] Cappuzzo F, Janne PA, Skokan M, Finocchiaro G, Rossi E, Ligorio C, et al. MET increased gene copy number and primary resistance to gefitinib therapy in non-small-cell lung cancer patients. Ann Oncol 2009;20(2):298-304 [Epub 2008/10/07].

[42] Turke AB, Zejnullahu K, Wu YL, Song Y, Dias-Santagata D, Lifshits E, et al. Preexistence and clonal selection of MET amplification in EGFR mutant NSCLC. Cancer Cell 2010;17(1):77-88 [Epub 2010/02/05].

[43] Yano S, Yamada T, Takeuchi S, Tachibana K, Minami Y, Yatabe Y, et al. Hepatocyte growth factor expression in EGFR mutant lung cancer with intrinsic and acquired resistance to tyrosine kinase inhibitors in a Japanese cohort. J Thorac Oncol 2011:6(12):2011-7 [Epub 2011/11/05].

[44] Donev IS, Wang W, Yamada T, Li Q, Takeuchi S, Matsumoto K, et al. Transient PI3K inhibition induces apoptosis and overcomes HGF-mediated resistance to EGFR-TKIs in EGFR mutant lung cancer. Clin Cancer Res 2011;17(8):2260-9 [Epub 2011/01/12].

[45] Uramoto H, Yamada T, Yano S, Kondo N, Hasegawa S, Tanaka F. Prognostic value of acquired resistance-related molecules in Japanese patients with NSCLC treated with an EGFR-TKI. Anticancer Res 2012;32(9):3785-90 [Epub 2012/09/2].

[46] Zhang Z, Lee JC, Lin L, Olivas V, Au V, LaFramboise T, et al. Activation of the AXL kinase causes resistance to EGFR-targeted therapy in lung cancer. Nat Genet 2012;44(8):852-60 [Epub 2012/07/04].

[47] Sequist LV, Waltman BA, Dias-Santagata D, Digumarthy S, Turke AB, Fidias P, et al. Genotypic and histological evolution of lung cancers acquiring resistance to EGFR inhibitors. Sci Transl Med. 2011;3(75):75ra26 [Epub 2011/03/25].

[48] Thomson S, Buck E, Petti F, Griffin G, Brown E, Ramnarine N, et al. Epithelial to mesenchymal transition is a determinant of sensitivity of non-small-cell lung carcinoma cell lines and xenografts to epidermal growth factor receptor inhibition. Cancer Res 2005;65(20):9455-62 [Epub 2005/10/19].

[49] Huang S, Holzel M, Knijnenburg T, Schlicker A, Roepman P, McDermott U, et al. MED12 controls the response to multiple cancer drugs through regulation of TGF-beta receptor signaling. Cell 2012;151(5):937-50 [Epub 2012/11/28].

[50] Suda K, Tomizawa K, Fujii M, Murakami H, Osada $H$, Maehara Y, et al Epithelial to mesenchymal transition in an epidermal growth factor receptormutant lung cancer cell line with acquired resistance to erlotinib. J Thorac Oncol 2011;6(7):1152-61 [Epub 2011/05/21].

[51] Yu HA, Arcila ME, Rekhtman N, Sima CS, Zakowski MF, Pao W, et al. Analysis of tumor specimens at the time of acquired resistance to EGFR-TKI therapy in 155 patients with EGFR-mutant lung cancers. Clin Cancer Res 2013:19(8):2240-7 [Epub 2013/03/09].

[52] Cheung HW, Du J, Boehm JS, He F, Weir BA, Wang X, et al. Amplification of CRKL induces transformation and epidermal growth factor receptor inhibitor resistance in human non-small cell lung cancers. Cancer Discov 2011;1(7):608-25 [Epub 2012/05/16].

[53] Kim YH, Kwei KA, Girard L, Salari K, Kao J, Pacyna-Gengelbach M, et al. Genomic and functional analysis identifies CRKL as an oncogene amplified in lung cancer. Oncogene 2010;29(10):1421-30 [Epub 2009/12/08].

[54] Camp ER, Summy J, Bauer TW, Liu W, Gallick GE, Ellis LM. Molecular mechanisms of resistance to therapies targeting the epidermal growth factor receptor. Clin Cancer Res 2005;11(1):397-405 [Epub 2005/01/27]. 
[55] Chakravarti A, Loeffler JS, Dyson NJ. Insulin-like growth factor receptor I mediates resistance to anti-epidermal growth factor receptor therapy in primary human glioblastoma cells through continued activation of phosphoinositide 3-kinase signaling. Cancer Res 2002;62(1):200-7 [Epub 2002/01/10].

[56] Ohashi K, Sequist LV, Arcila ME, Moran T, Chmielecki J, Lin YL, et al. Lung cancers with acquired resistance to EGFR inhibitors occasionally harbor BRAF gene mutations but lack mutations in KRAS, NRAS, or MEK1. Proc Natl Acad Sci USA 2012;109(31):E2127-33 [Epub 2012/07/10].

[57] Takezawa K, Pirazzoli V, Arcila ME, Nebhan CA, Song X, de Stanchina E, et al. HER2 amplification: a potential mechanism of acquired resistance to EGFR inhibition in EGFR-mutant lung cancers that lack the second-site EGFRT790M mutation. Cancer Discov 2012;2(10):922-33 [Epub 2012/09/08].

[58] Ercan D, Xu C, Yanagita M, Monast CS, Pratilas CA, Montero J, et al. Reactivation of ERK signaling causes resistance to EGFR kinase inhibitors, Cancer Discov 2012;2(10):934-47 [Epub 2012/09/11].

[59] De Bruin EC, Cowell C, Warne PH, Jiang M, Saunders RE, Melnick MA, et al. Reduced NF1 expression confers resistance to EGFR inhibition in lung cancer. Cancer Discov. 2014; 4(5): 606-19. doi: 10.1158/2159-8290. CD-13-0741 [Epub 2014 Feb 17].

[60] Harada D, Takigawa N, Ochi N, Ninomiya T, Yasugi M, Kubo T, et al. JAK2related pathway induces acquired erlotinib resistance in lung cancer cells harboring an epidermal growth factor receptor-activating mutation. Cancer Sci 2012;103(10):1795-802 [Epub 2012/06/21].

[61] Rosell R, Moran T, Queralt C, Porta R, Cardenal F, Camps C, et al. Screening for epidermal growth factor receptor mutations in lung cancer. N Engl J Med 2009;361(10):958-67 [Epub 2009/08/21].

[62] Taron M, Benlloch S, Rosell R, Sanchez JJ, Costa C, Gimenez Capitan A, et al. Identification of AEG-1 and BARD1 as predictors of erlotinib outcome in EGFR-mutant non-small cell lung cancer (NSCLC) by NanoString multiple target profiling. J Clin Oncol 2011;29 [suppl; abstr 7589].

[63] Jiang B, Liu F, Yang L, Zhang W, Yuan H, Wang J, et al. Serum detection of epidermal growth factor receptor gene mutations using mutant-enriched sequencing in Chinese patients with advanced non-small cell lung cancer. J Int Med Res 2011;39(4):1392-401 [Epub 2011/10/12].

[64] Nakamura T, Sueoka-Aragane N, Iwanaga K, Sato A, Komiya K, Abe T, et al. A noninvasive system for monitoring resistance to epidermal growth factor receptor tyrosine kinase inhibitors with plasma DNA. J Thorac Oncol 2011;6(10):1639-48 [Epub 2011/09/17].

[65] Li D, Ambrogio L, Shimamura T, Kubo S, Takahashi M, Chirieac LR, et al. BIBW2992, an irreversible EGFR/HER2 inhibitor highly effective in preclinical lung cancer models. Oncogene 2008;27(34):4702-11 [Epub 2008/04/15].

[66] Solca F, Dahl G, Zoephel A, Bader G, Sanderson M, Klein C, et al. Target binding properties and cellular activity of afatinib (BIBW 2992), an irreversible ErbB family blocker. J Pharmacol Exp Ther 2012;343(2):342-50 [Epub 2012/08/ 14].

[67] Wind S, Giessmann T, Jungnik A, Brand T, Marzin K, Bertulis J, et al. Pharmacokinetic drug interactions of afatinib with rifampicin and ritonavir. Clin Drug Investig 2014;34(3):173-82 [Epub 2014/01/09].

[68] Ingelheim B. GILOTRIF prescribing information. 2013 [cited 2014 March 2014]; Available from: <http://www.accessdata.fda.gov/drugsatfda_docs/ label/2013/201292s000lbl.pdf>.

[69] Wind S, Schmid M, Erhardt J, Goeldner RG, Stopfer P. Pharmacokinetics of afatinib, a selective irreversible ErbB family blocker, in patients with advanced solid tumours. Clin Pharmacokinet 2013;52(12):1101-9 [Epub 2013/07/03].

[70] Hirsh V. Afatinib (BIBW 2992) development in non-small-cell lung cancer. Future Oncol 2011:7(7):817-25 [Epub 2011/07/08].

[71] Miller VA, Hirsh V, Cadranel J, Chen YM, Park K, Kim SW, et al. Afatinib versus placebo for patients with advanced, metastatic non-small-cell lung cancer after failure of erlotinib, gefitinib, or both, and one or two lines of chemotherapy (LUX-Lung 1): a phase $2 \mathrm{~b} / 3$ randomised trial. Lancet Oncol 2012;13(5):528-38 [Epub 2012/03/29].

[72] Hirsh V, Cadranel J, Cong XJ, Fairclough D, Finnern HW, Lorence RM, et al. Symptom and quality of life benefit of afatinib in advanced non-small-cell lung cancer patients previously treated with erlotinib or gefitinib: results of a randomized phase IIb/III trial (LUX-Lung 1). J Thorac Oncol 2013;8(2):229-37 [Epub 2013/01/19].

[73] Yang JC, Shih JY, Su WC, Hsia TC, Tsai CM, Ou SH, et al. Afatinib for patients with lung adenocarcinoma and epidermal growth factor receptor mutations (LUX-Lung 2): a phase 2 trial. Lancet Oncol 2012;13(5):539-48 [Epub 2012/ 03/29].

[74] Sequist LV, Yang JC, Yamamoto N, O’Byrne K, Hirsh V, Mok T, et al. Phase III study of afatinib or cisplatin plus pemetrexed in patients with metastatic lung adenocarcinoma with EGFR mutations. J Clin Oncol 2013;31(27):3327-34. http://dx.doi.org/10.1200/JCO.2012.44.2806 [Epub 2013 Jul 1].

[75] Wu YL, Zhou C, Hu CP, Feng J, Lu S, Huang Y, et al. Afatinib versus cisplatin plus gemcitabine for first-line treatment of Asian patients with advanced non-small-cell lung cancer harbouring EGFR mutations (LUX-Lung 6): an open-label, randomised phase 3 trial. Lancet Oncol 2014;15(2):213-22 [Epub 2014/01/21].

[76] Lacouture ME, Schadendorf D, Chu CY, Uttenreuther-Fischer M, Stammberger U, O'Brien D, et al. Dermatologic adverse events associated with afatinib: an oral ErbB family blocker. Expert Rev Anticancer Ther 2013;13(6):721-8 [Epub 2013/03/20].
[77] Yang JC, Reguart N, Barinoff J, Kohler J, Uttenreuther-Fischer M, Stammberger U, et al. Diarrhea associated with afatinib: an oral ErbB family blocker. Expert Rev Anticancer Ther 2013;13(6):729-36 [Epub 2013/03/20].

[78] Yang JC, Sequist L, Geater SL, Tsai CM, Mok T, Schuler M, et al. Activity of afatinib in uncommon epidermal growth factor receptor (EGFR) mutations: findings from three trials of afatinib in EGFR mutation-positive lung cancer. J Thorac Oncol 2013;8(Suppl 2) [Abstract O03.5].

[79] Regales L, Gong Y, Shen R, de Stanchina E, Vivanco I, Goel A, et al. Dual targeting of EGFR can overcome a major drug resistance mutation in mouse models of EGFR mutant lung cancer. J Clin Investig 2009;119(10):3000-10 [Epub 2009/09/18].

[80] Giaccone G, Wang Y. Strategies for overcoming resistance to EGFR family tyrosine kinase inhibitors. Cancer Treat Rev 2011;37(6):456-64 [Epub 2011/ 03/04].

[81] Janjigian Y, Groen H, Horn L, Smit E, Fu Y, Wang F, et al. Activity and tolerability of afatinib (BIBW 2992) and cetuximab in NSCLC patients with acquired resistance to erlotinib or gefitinib. J Clin Oncol 2011;29(Suppl.) [Abstract 7525].

[82] Janjigian YY, Azzoli CG, Krug LM, Pereira LK, Rizvi NA, Pietanza MC, et al. Phase I/II trial of cetuximab and erlotinib in patients with lung adenocarcinoma and acquired resistance to erlotinib. Clin Cancer Res 2011;17(8):2521-7 [Epub 2011/01/21].

[83] Engelman JA, Zejnullahu K, Gale CM, Lifshits E, Gonzales AJ, Shimamura T, et al. PF00299804, an irreversible pan-ERBB inhibitor, is effective in lung cancer models with EGFR and ERBB2 mutations that are resistant to gefitinib. Cancer Res 2007;67(24):11924-32 [Epub 2007/12/20].

[84] Giri N, Plotka A, Laing Y, Boutros T, Ni G, Masters J, et al. Influence of mild and moderate hepatic impairment on the pharmacokinetics (PK) of the pan-HER inhibitor dacomitinib. J Clin Oncol 2013;31(Suppl) [Abstract 2568].

[85] Janne PA, Reckamp K, Koczywas M, Engelman JA, Camidge DR, Rajan A, et al Efficacy and safety of PF-00299804 (PF299) in patients (pt) with advanced NSCLC after failure of at least one prior chemotherapy regimen and prior treatment with erlotinib (E): a two-arm, phase II trial. J Clin Oncol 2009;27(15S):1.

[86] Mok T, Spigel DR, Park K, Socinski MA, Tung SY, Kim D, et al. Efficacy and safety of PF-00299804 (PF299), an oral, irreversible, pan-human epidermal growth factor receptor (pan-HER) tyrosine kinase inhibitor (TKI), as first-line treatment (tx) of selected patients (pts) with advanced (adv) non-small cell lung cancer (NSCLC). J Clin Oncol 2010;28(15s) [suppl; abstr 7537].

[87] Boyer MJ, Blackhall FH, Park K, Barrios CH, Krzakowski MJ, Taylor I, et al. Efficacy and safety of PF299804 versus erlotinib (E): a global, randomized phase II trial in patients (pts) with advanced non-small cell lung cancer (NSCLC) after failure of chemotherapy (CT). J Clin Oncol, 2010 ASCO Annual Meeting Abstracts, vol. 28, No. 18_suppl (June 20 Supplement), 2010: LBA7523.

[88] Campbell A, Reckamp K, Camidge D, Giaccone G, Gadgeel S, Khuri F, et al. PF00299804 (PF299) patient (pt)-reported outcomes (PROs) and efficacy in adenocarcinoma (adeno) and nonadeno non-small cell lung cancer (NSCLC): a phase (P) II trial in advanced NSCLC after failure of chemotherapy (CT) and erlotinib (E). Chicago: ASCO: J Clin Oncol 2010; 28(15s) [suppl; abstr 7596].

[89] Kris M, Mok T, Ou S-H, Martins R, Kim D-W, Goldberg Z, et al. First-line dacomitinib (PF-00299804), an irreversible pan-HER tyrosine kinase inhibitor for patients with EGFR-mutant lung cancer. Chicago, IL: ASCO, J Clin Onco 2012; 30 [suppl; abstr 7530].

[90] Boyer M, Blackhall F, Barrios C, et al. 14th World Congress on Lung Cancer; Amsterdam 2011; p. Abstr 745.

[91] Boyer M, Janne P, Mok T, O’Byrne K, Paz-Ares L, Ramalingam S, et al. ARCHER: a randomized doubled-bilnded phase III study of dacomitinib (PF-00299804) versus erlotinib for advanced non-smell cell lung cancer. Chicago, IL; ASCO. J Clin Oncol 2012; 30 [suppl; abstr TPS7615].

[92] Pfizer. Pfizer announces top-line results from two phase 3 trials of dacomitinib in patients with refractory advanced non-small cell lung cancer 2014 [cited 20141 April]; Available from: <http://www.pfizer.com/ news/press-release/press-release-detail/pfizer_announces_top_line_results_ from_two_phase_3_trials_of_dacomitinib_in_patients_with_refractory_ advanced_non_small_cell_lung_cancer>.

[93] Ranson M, Pao W, Kim D, Kim SW, Ohe Y, Felip E, et al. An irrerversible, potent and selective tyrosine kinase inhibitor (TKI) of activating (EGFRM+) and resistance (T790M) mutations in advanced NSCLC. J Thorac Oncol 2014;8(Suppl 2) [Abstract MO21.12].

[94] Ranson M, Pao W, Kim D, Kim SW, Ohe Y, Felip E, et al. Preliminary results from a Phase I study with AZD9291: an irreversible inhibitor of epidermal growth factor receptor (EGFR) activating and resistance mutations in nonsmall-cell lung cancer (NSCLC). Presented at the European Cancer Congress 2013, Amsterdam, The Netherlands, 27th September to 1st October 2013. 2013:LBA 33

[95] Walter AO, Sjin RT, Haringsma HJ, Ohashi K, Sun J, Lee K, et al. Discovery of a mutant-selective covalent inhibitor of EGFR that overcomes T790Mmediated resistance in NSCLC. Cancer Discov 2013;3(12):1404-15 [Epub 2013/09/26].

[96] Soria J, Sequist L, Gadgeel SM, Goldman J, Wakelee H, Varga A, et al. First inhuman evaluation of CO-1686, an irreversible, highly slective tyrosine kinase inhibitor of mutations of EGFR (activating and T790M). J Thorac Oncol 2013;8(Suppl 2) [Abstract 003.6].

[97] Pietanza MC, Gadgeel SM, Dowlati A, Lynch TJ, Salgia R, Rowland Jr KM, et al Phase II study of the multitargeted tyrosine kinase inhibitor XL647 in patients 
with non-small-cell lung cancer. J Thorac Oncol 2012;7(5):856-65 [Epub 2012/06/23].

[98] Li D, Shimamura T, Ji H, Chen L, Haringsma HJ, McNamara K, et al. Bronchial and peripheral murine lung carcinomas induced by T790M-L858R mutant EGFR respond to HKI-272 and rapamycin combination therapy. Cancer Cell 2007;12(1):81-93 [Epub 2007/07/07].

[99] Zhao Q, Shentu J, Xu N, Zhou J, Yang G, Yao Y, et al. Phase I study of icotinib hydrochloride (BPI-2009H), an oral EGFR tyrosine kinase inhibitor, in patients with advanced NSCLC and other solid tumors. Lung Cance 2011;73(2):195-202 [Epub 2010/12/15].

[100] Tan F, Shen X, Wang D, Xie G, Zhang X, Ding L, et al. Icotinib (BPI-2009H), a novel EGFR tyrosine kinase inhibitor, displays potent efficacy in preclinical studies. Lung Cancer 2012;76(2):177-82 [Epub 2011/11/25].

[101] Doebele RC, Pilling AB, Aisner DL, Kutateladze TG, Le AT, Weickhardt AJ, et al Mechanisms of resistance to crizotinib in patients with ALK gene rearranged non-small cell lung cancer. Clin Cancer Res 2012;18(5):1472-82 [Epub 2012 $01 / 12]$.

[102] Govindan R. A review of epidermal growth factor receptor/HER2 inhibitors in the treatment of patients with non-small-cell lung cancer. Clin Lung Cancer 2010;11(1):8-12 [Epub 2010/01/21].

[103] Spigel DR, Ervin TJ, Ramlau RA, Daniel DB, Goldschmidt Jr JH, Blumenschein Jr GR, et al. Randomized phase II trial of Onartuzumab in combination with erlotinib in patients with advanced non-small-cell lung cancer. J Clin Oncol 2013;31(32):4105-14 [Epub 2013/10/09].

[104] Sequist LV, von Pawel J, Garmey EG, Akerley WL, Brugger W, Ferrari D, et al. Randomized phase II study of erlotinib plus tivantinib versus erlotinib plus placebo in previously treated non-small-cell lung cancer. J Clin Oncol 2011;29(24):3307-15 [Epub 2011/07/20].

[105] Scagliotti GV, Novello S, Schiller JH, Hirsh V, Sequist LV, Soria JC, et al Rationale and design of MARQUEE: a phase III, randomized, double-blind study of tivantinib plus erlotinib versus placebo plus erlotinib in previously treated patients with locally advanced or metastatic, nonsquamous, nonsmall-cell lung cancer. Clin Lung Cancer. 2012;13(5):391-5. http: dx.doi.org/10.1016/i.cllc.2012.01.003 [Epub 2012 Mar 21].

[106] Hewish M, Chau I, Cunningham D. Insulin-like growth factor 1 receptor targeted therapeutics: novel compounds and novel treatment strategies for cancer medicine. Recent Pat Anticancer Drug Discov 2009;4(1): $54-72$.

[107] Karp DD, Paz-Ares LG, Novello S, Haluska P, Garland L, Cardenal F, et al. Phase II study of the anti-insulin-like growth factor type 1 receptor antibody $\mathrm{CP}$ 751,871 in combination with paclitaxel and carboplatin in previously untreated, locally advanced, or metastatic non-small-cell lung cancer. J Clin Oncol 2009;27(15):2516-22 [Epub 2009/04/22].

[108] Ramalingam SS, Spigel DR, Chen D, Steins MB, Engelman JA, Schneider CP, et al. Randomized phase II study of erlotinib in combination with placebo or R1507, a monoclonal antibody to insulin-like growth factor-1 receptor, for advanced-stage non-small-cell lung cancer. J Clin Oncol 2011;29(34): 4574-80.

[109] Shimamura T, Li D, Ji H, Haringsma HJ, Liniker E, Borgman CL, et al. Hsp90 inhibition suppresses mutant EGFR-T790M signaling and overcomes kinase inhibitor resistance. Cancer Res 2008;68(14):5827-38 [Epub 2008/07/18].

[110] Ono N, Yamazaki T, Tsukaguchi T, Fujii T, Sakata K, Suda A, et al. Enhanced antitumor activity of erlotinib in combination with the Hsp90 inhibitor CH5164840 against non-small-cell lung cancer. Cancer Sci 2013;104(10): 1346-52 [Epub 2013/07/19].

[111] Johnson ML, Hart EM, Weitner BB, Uman A, Simm HD, Fountas LM, et al. A phase II study of HSP90 inhibitor AUY922 and erlotinib (E) for patients (pts) with EGFR-mutant lung cancer and acquired resistance (AR) to EGFR tyrosine kinase inhibitors (EGFR TKIs). J Clin Oncol 2013;31(Suppl.) [Abstract 8036].

[112] Felip Eea. Phase II activity of the HSP90 inhibitor AUY922 in patients with ALK-rearranged or EGFR mutated NSCLC. Ann Oncol 2012;23(Suppl 9):152-74.

[113] Gandhi L, Butaney M, Shaw A, Bahleda R, Fiel K, Wolanski A, et al. HER2 mutations in non-small cell lung cancer: preliminary efficacy of targeted therapy with neratinib + torisel on a phase I trial. Amsterdam: WCLC; 2011 [p. Abstr MO21.14].

[114] Soria JC, Shepherd FA, Douillard JY, Wolf J, Giaccone G, Crino L, et al. Efficacy of everolimus (RAD001) in patients with advanced NSCLC previously treated with chemotherapy alone or with chemotherapy and EGFR inhibitors. Ann Oncol 2009;20(10):1674-81 [Epub 2009/06/25].

[115] Leigh NBl, Soria J, Bennouna J, Blais N, Traynor AM, Papadimitrakopoulou V, et al. Phase II study of everolimus plus erlotinib in previously treated patients with advanced non-small cell lung cancer (NSCLC). J Clin Oncol, 2010 ASCO Annual Meeting Abstracts. vol. 28, No. 15_suppl (May 20 Supplement), 2010 7524.

[116] Ratnam K, Low JA. Current development of clinical inhibitors of poly(ADPribose) polymerase in oncology. Clin Cancer Res 2007;13(5):1383-8.

[117] Traynor AM, Schiller JH, Stabile LP, Kolesar JM, Eickhoff JC, Dacic S, et al. Pilot study of gefitinib and fulvestrant in the treatment of post-menopausa women with advanced non-small cell lung cancer. Lung Cancer 2009;64(1):51-9.

[118] Bazhenova L, Quintana R, Hastings R, Messer K. Phase II trial evaluating addition of fulvestrant to erlotinib in patients with stage IIIb/IV non-small cell lung cancer (NSCLC) who are stable on erlotinib and exhibit immunohistochemical (IHC) or PCR positivity for estrogen or progesterone receptor (PR). J Clin Oncol 2010;28(Suppl. 15) [Abstract TPS294].
[119] Garon E, Dubinett S, Kabbinavar F, Reckamp K, Marquez-Garban D, Goodglick L, et al. Randomized, multicenter phase II study of erlotinib (E) or E plus fulvestrant $(\mathrm{F})$ in previously treated advanced non-small cell lung cancer (NSCLC). Chicago, IL: ASCO; J Clin Oncol 2011; p. Abstr TPS216, 29: 2011 [suppl; abstr TPS216].

[120] Stabile LP, Lyker JS, Gubish CT, Zhang W, Grandis JR, Siegfried JM. Combined targeting of the estrogen receptor and the epidermal growth factor receptor in non-small cell lung cancer shows enhanced antiproliferative effects. Cancer Res 2005;65(4):1459-70 [Epub 2005/03/01].

[121] Raso MG, Behrens C, Herynk MH, Liu S, Prudkin L, Ozburn NC, et al. Immunohistochemical expression of estrogen and progesterone receptors identifies a subset of NSCLCs and correlates with EGFR mutation. Clin Cancer Res 2009;15(17):5359-68 [Epub 2009/08/27].

[122] Mazieres J, Rouquette I, Lepage B, Milia J, Brouchet L, Guibert N, et al. Specificities of lung adenocarcinoma in women who have never smoked. ] Thorac Oncol 2013:8(7):923-9 [Epub 2013/04/24].

[123] Witta SE, Dziadziuszko R, Yoshida K, Hedman K, Varella-Garcia M, Bunn Jr PA, et al. ErbB-3 expression is associated with E-cadherin and their coexpression restores response to gefitinib in non-small-cell lung cancer (NSCLC). Ann Oncol 2009;20(4):689-95 [Epub 2009/01/20].

[124] Nakagawa T, Takeuchi S, Yamada T, Ebi H, Sano T, Nanjo S, et al. EGFR-TKI resistance due to BIM polymorphism can be circumvented in combination with HDAC inhibition. Cancer Res 2013; 73(8): 2428-34, doi: 10.1158/00085472. CAN-12-3479 [Epub 2013 Feb 4].

[125] Reguart N, Rosell R, Cardenal F, Cardona AF, Isla D, Palmero R, et al. Phase I/II trial of vorinostat (SAHA) and erlotinib for non-small cell lung cancer (NSCLC) patients with epidermal growth factor receptor (EGFR) mutations after erlotinib progression. Lung Cancer 2014;84(2):161-7. http://dx.doi.org/ 10.1016/i.lungcan.2014.02.011 [Epub 2014 Mar 2].

[126] Witta SE, Jotte RM, Konduri K, Neubauer MA, Spira AI, Ruxer RL, et al. Randomized phase II trial of erlotinib with and without entinostat in patients with advanced non-small-cell lung cancer who progressed on prior chemotherapy. J Clin Oncol 2012;30(18):2248-55 [Epub 2012/04/18].

[127] Riely GJ, Kris MG, Zhao B, Akhurst T, Milton DT, Moore E, et al. Prospective assessment of discontinuation and reinitiation of erlotinib or gefitinib in patients with acquired resistance to erlotinib or gefitinib followed by the addition of everolimus. Clin Cancer Res 2007:13(17):5150-5 [Epub 2007/09/ 06].

[128] Chaft JE, Oxnard GR, Sima CS, Kris MG, Miller VA, Riely GJ. Disease flare after tyrosine kinase inhibitor discontinuation in patients with EGFR-mutant lung cancer and acquired resistance to erlotinib or gefitinib: implications for clinical trial design. Clin Cancer Res 2011;17(19):6298-303 [Epub 2011/08/ 23].

[129] Shukuya T, Takahashi T, Naito T, Kaira R, Ono A, Nakamura Y, et al Continuous EGFR-TKI administration following radiotherapy for non-small cell lung cancer patients with isolated CNS failure. Lung Cancer 2011:74(3):457-61 [Epub 2011/05/17].

[130] Inomata M, Shukuya T, Takahashi T, Ono A, Nakamura Y, Tsuya A, et al. Continuous administration of EGFR-TKIs following radiotherapy after disease progression in bone lesions for non-small cell lung cancer. Anticancer Res 2011:31(12):4519-23.

[131] Schuler M, Planchard D, Yang J, Kim J-H, De Marinis F, Chen Y-M, et al. Interim analysis of afatinib monotherapy in patients with metastatic NSCLC progressing after chemotherapy and erlotinib/gefitinib (E/G) in a trial of afatinib plus paclitaxel vs. investigator's choice chemotherapy following progression on afatinib monotherapy. J Clin Oncol 2012;30(Suppl.) [Abstract 7557].

[132] Becker A, Crombag L, Heideman DA, Thunnissen FB, van Wijk AW, Postmus $\mathrm{PE}$, et al. Retreatment with erlotinib: regain of TKI sensitivity following a drug holiday for patients with NSCLC who initially responded to EGFR-TKI treatment. Eur J Cancer 2011:47(17):2603-6 [Epub 2011/07/26].

[133] Yokouchi H, Yamazaki K, Kinoshita I, Konishi J, Asahina H, Sukoh N, et al. Clinical benefit of readministration of gefitinib for initial gefitinib-responders with non-small cell lung cancer. BMC Cancer 2007;7:51 [Epub 2007/03/22].

[134] Albanese A, Colosimo C, Bentivoglio AR, Fenici R, Tonali P. Correlation of cardiovascular autonomic function tests, magnetic resonance brain imaging and clinical features in suspect cases of multiple system atrophy. Funct Neurol 1991:6(3):269-73 [Epub 1991/07/01].

[135] Yano S, Nakataki E, Ohtsuka S, Inayama M, Tomimoto H, Edakuni N, et al. Retreatment of lung adenocarcinoma patients with gefitinib who had experienced favorable results from their initial treatment with this selective epidermal growth factor receptor inhibitor: a report of three cases. Oncol Res 2005;15(2):107-11 [Epub 2005/08/27].

[136] Kurata T, Tamura K, Kaneda H, Nogami T, Uejima H, Asai Go G, et al. Effect of re-treatment with gefitinib ('Iressa', ZD1839) after acquisition of resistance. Ann Oncol 2004;15(1):173-4 [Epub 2003/12/18].

[137] Watanabe S, Tanaka J, Ota T, Kondo R, Tanaka H, Kagamu H, et al. Clinical responses to EGFR-tyrosine kinase inhibitor retreatment in non-small cell lung cancer patients who benefited from prior effective gefitinib therapy: a retrospective analysis. BMC Cancer 2011;11:1 [Epub 2011/01/05].

[138] Sim SH, Han SW, Oh DY, Lee SH, Kim DW, Im SA, et al. Erlotinib after Gefitinib failure in female never-smoker Asian patients with pulmonary adenocarcinoma. Lung Cancer 2009;65(2):204-7 [Epub 2008/12/27].

[139] Lee DH, Kim SW, Suh C, Yoon DH, Yi EJ, Lee JS. Phase II study of erlotinib as a salvage treatment for non-small-cell lung cancer patients after failure of gefitinib treatment. Ann Oncol 2008;19(12):2039-42 [Epub 2008/07/23]. 
[140] Wong MK, Lo AI, Lam B, Lam WK, Ip MS, Ho JC. Erlotinib as salvage treatment after failure to first-line gefitinib in non-small cell lung cancer. Cancer Chemother Pharmacol 2010;65(6):1023-8 [Epub 2009/08/15].

[141] Wong AS, Soong R, Seah SB, Lim SW, Chuah KL, Nga ME, et al. Evidence for disease control with erlotinib after gefitinib failure in typical gefitinibsensitive Asian patients with non-small cell lung cancer. J Thorac Oncol 2008;3(4):400-4 [Epub 2008/04/02].

[142] Cho BC, Im CK, Park MS, Kim SK, Chang J, Park JP, et al. Phase II study of erlotinib in advanced non-small-cell lung cancer after failure of gefitinib. J Clin Oncol 2007;25(18):2528-33 [Epub 2007/06/20].

[143] Costa DB, Nguyen KS, Cho BC, Sequist LV, Jackman DM, Riely GJ, et al. Effects of erlotinib in EGFR mutated non-small cell lung cancers with resistance to gefitinib. Clin Cancer Res 2008;14(21):7060-7 [Epub 2008/11/05].

[144] Kaira K, Naito T, Takahashi T, Ayabe E, Shimoyama R, Kaira R, et al. Pooled analysis of the reports of erlotinib after failure of gefitinib for non-small cell lung cancer. Lung Cancer 2010;68(1):99-104 [Epub 2009/06/23].

[145] Chmielecki J, Foo J, Oxnard GR, Hutchinson K, Ohashi K, Somwar R, et al. Optimization of dosing for EGFR-mutant non-small cell lung cancer with evolutionary cancer modeling. Sci Transl Med 2011;3(90):90ra59.

[146] Foo J, Chmielecki J, Pao W, Michor F. Effects of pharmacokinetic processes and varied dosing schedules on the dynamics of acquired resistance to erlotinib in EGFR-mutant lung cancer. J Thorac Oncol 2012;7(10):1583-93 [Epub 2012/ 09/18].

[147] Gow CH, Chien CR, Chang YL, Chiu YH, Kuo SH, Shih JY, et al. Radiotherapy in lung adenocarcinoma with brain metastases: effects of activating epidermal growth factor receptor mutations on clinical response. Clin Cancer Res 2008;14(1):162-8 [Epub 2008/01/04].

[148] Huang SM, Li J, Armstrong EA, Harari PM. Modulation of radiation response and tumor-induced angiogenesis after epidermal growth factor receptor inhibition by ZD1839 (Iressa). Cancer Res 2002;62(15):4300-6.

[149] Chang CC, Chi KH, Kao SJ, Hsu PS, Tsang YW, Chang HJ, et al. Upfront gefitinib/ erlotinib treatment followed by concomitant radiotherapy for advanced lung cancer: a mono-institutional experience. Lung Cancer 2011;73(2):189-94.
[150] Weickhardt AJ, Scheier B, Burke JM, Gan G, Lu X, Bunn Jr PA, et al. Local ablative therapy of oligoprogressive disease prolongs disease control by tyrosine kinase inhibitors in oncogene-addicted non-small-cell lung cancer. J Thorac Oncol 2012;7(12):1807-14 [Epub 2012/11/17].

[151] Giaccone G, Herbst RS, Manegold C, Scagliotti G, Rosell R, Miller V, et al. Gefitinib in combination with gemcitabine and cisplatin in advanced nonsmall-cell lung cancer: a phase III trial - INTACT 1. J Clin Oncol 2004;22(5):777-84 [Epub 2004/03/03].

[152] Gatzemeier U, Pluzanska A, Szczesna A, Kaukel E, Roubec J, De Rosa F, et al. Phase III study of erlotinib in combination with cisplatin and gemcitabine in advanced non-small-cell lung cancer: the Tarceva Lung Cancer Investigation Trial. J Clin Oncol 2007;25(12):1545-52 [Epub 2007/04/20].

[153] Hirsch FR, Kabbinavar F, Eisen T, Martins R, Schnell FM, Dziadziuszko R, et al. A randomized, phase II, biomarker-selected study comparing erlotinib to erlotinib intercalated with chemotherapy in first-line therapy for advanced non-small-cell lung cancer. J Clin Oncol 2011;29(26):3567-73 [Epub 2011/ 08/10].

[154] Wu YL, Lee JS, Thongprasert S, Yu CJ, Zhang L, Ladrera G, et al. Intercalated combination of chemotherapy and erlotinib for patients with advanced stage non-small-cell lung cancer (FASTACT-2): a randomised, double-blind trial. Lancet Oncol 2013;14(8):777-86 [Epub 2013/06/21].

[155] Fukuoka M, Wu YL, Thongprasert S, Sunpaweravong P, Leong SS, Sriuranpong $\mathrm{V}$, et al. Biomarker analyses and final overall survival results from a phase III randomized, open-label, first-line study of gefitinib versus carboplatin/ paclitaxel in clinically selected patients with advanced non-small-cell lung cancer in Asia (IPASS). J Clin Oncol 2011:29(21):2866-74 [Epub 2011/06/15]

[156] Sequist LV, Yang JC, Yamamoto N, O’Byrne K, Hirsh V, Mok T, et al. Phase IIl study of afatinib or cisplatin plus pemetrexed in patients with metastatic lung adenocarcinoma with EGFR mutations. J Clin Oncol 2013;31(27): 3327-34 [Epub 2013/07/03]. 